\title{
Diatomáceas perifíticas em Polygonum hydropiperoides Michaux, reservatório do Passaúna, Região Metropolitana de Curitiba, Paraná, Brasil
}

\author{
Lucielle Merlym Bertolli1,3, Priscila Izabel Tremarin² e Thelma Alvim Veiga Ludwig ${ }^{1}$
}

Recebido em 23/04/2010. Aceito em 02/12/2010

\begin{abstract}
RESUMO - (Diatomáceas perifíticas em Polygonum hydropiperoides Michaux, reservatório do Passaúna, Paraná, Brasil). A diatomoflórula perifítica aderida a Polygonum hydropiperoides Michaux foi estudada em um plano amostral trimestral, no reservatório do rio Passaúna, estado do Paraná, Brasil. Partes da macrófita foram raspadas para a retirada do perifíton, que foi oxidado para a confecção de lâminas permanentes. Cento e seis táxons foram observados e suas dimensões e ilustrações foram apresentadas. Fragilariaceae foi a família mais representativa, com oito gêneros. Entre os 39 gêneros observados Navicula Bory, Gomphonema Ehrenberg e Nitzschia Hassall apresentaram as maiores riquezas taxonômicas. Quinze novos registros para o estado do Paraná foram descritos.
\end{abstract}

Palavras-chave: Diatomeae, ambiente lêntico, epifíton, taxonomia

\begin{abstract}
Periphytic diatoms on Polygonum hydropiperoides Michaux, Passaúna reservoir, Paraná State, Brazil). The periphytic diatoms attached to Polygonum hydropiperoides Michaux were studied with sampling, in the reservoir of the Passaúna river, Paraná State, Brazil. Parts of the macrophyte were scraped to remove the periphytic matrix which was cleaned to make permanent slides. One hundred and six taxa were determined. Fragilariaceae was the most representative family, with eight genera. Navicula Bory, Gomphonema Ehrenberg and Nitzschia Hassall showed the greater species richness among the 39 genera observed. Fifteen taxa are new records to Paraná state.
\end{abstract}

Key words: Diatomeae, lentic environment, epiphyton, taxonomy

\section{Introdução}

Perifíton é o conjunto de microrganismos e partículas orgânicas e inorgânicas aderido, firme ou frouxamente, a diferentes tipos de substratos submersos. Entre os tipos de substratos aquáticos disponíveis, as macrófitas disponibilizam extensas superfícies para a colonização (Wetzel 1983). As diatomáceas destacam-se entre os microorganismos autotróficos perifíticos, sendo frequentemente a classe algal predominante nesta comunidade (Pompêo et al. 2003). Muitas espécies aderem-se às superfícies por mucilagem secretada através de estruturas como campo de poros apical, rafe e rimopórtula (Round et al. 1990), estratégias que lhes conferem vantagens adaptativas (Fernandes 2005, Lowe 1996).

Os estudos florísiticos sobre diatomáceas perifíticas no Paraná iniciaram-se em 1973, quando Moreira-Filho et al. (1973) realizaram um trabalho na barragem do rio Iguaçu, em que foram utilizadas amostras retiradas de órgãos submersos de vegetais. Inicialmente, a remoção do material era realizada por meio da agitação das macrófitas em água, ou era utilizado o espremido de partes submersas de plantas e, frequentemente, as amostras eram completadas com água do local (Shirata \& Valente-Moreira 1987, Ludwig \& ValenteMoreira 1989, 1990, Lozovei \& Shirata 1990). Ao longo dos anos, os estudos das diatomáceas perifíticas tornaram-se mais freqüentes no Estado, principalmente em ambientes reófilos, embora muitos destes não tenham sido publicados (Tremarin et al. 2009b).

$\mathrm{Na}$ última década, publicações sobre a diatomoflórula epifítica em ambientes lênticos no Paraná foram as de Fürstenberger \& Valente-Moreira (2000a,b), Tavares \& ValenteMoreira (2000), Cetto et al. (2004), Ludwig et al. (2005),
Felisberto \& Rodrigues (2005) e Tremarin et al. (2009a).

Para o Brasil, destaca-se o uso das diatomáceas epilíticas como bioindicadoras da qualidade da água (Rodrigues \& Lobo 2000, Oliveira et al. 2001, Lobo et al. 2002, 2004 Salomoni et al. 2006, Hermany et al. 2006) e das epifíticas nas contribuições de Souza \& Moreira-Filho (1999 a, b) em bancos de macrófitas da Lagoa Bonita (DF); Rodrigues \& Bicudo (2001) em um gradiente lêntico-lótico na divisa entre Paraná e Mato Grosso do Sul; Fernandes \& Esteves (2003), na lagoa Imboassica (RJ); Ludwig et al. (2004) em lagoas do Sistema Hidrológico do Taim (RS) e Ferrari et al. (2007) em igarapés da Amazônia Central.

Este estudo teve por objetivo inventariar as diatomáceas perifiticas aderidas a Polygonum hydropiperoides Michaux no reservatório do Passaúna, providenciando ilustrações, medidas e descrições e comentários taxonômicos para os táxons registrados pela primeira vez para o Paraná, contribuindo-se, desta forma, para o conhecimento das diatomáceas perifíticas do Estado.

\section{Material e métodos}

A sub-bacia do Passaúna está localizada no primeiro planalto paranaense, com altitude média de $900 \mathrm{~m}$ acima do nível do mar. O clima na região é caracterizado como mesotérmico úmido, sem estação seca, com temperatura média do mês mais quente inferior a $22{ }^{\circ} \mathrm{C}$ e verões frescos (Maack, 1981). O reservatório do Passaúna foi formado pela barragem do rio de mesmo nome entre 1985 e 1989 e compreende uma área inundada de $10,5 \mathrm{~km}^{2}$, próximo à região industrial de Araucária (Smaha \& Gobbi 2003, Sauniti et al. 2004). A Área de Proteção Ambiental do Passaúna abrange a área alagada e seu entorno e integra o Plano de Recursos Hídricos da Bacia Hidrográfica do Alto Iguaçu, que visa a proteção e a conservação da qualidade da água em sistemas utilizados para abastecimento público (Gobbi \& Smaha 2003). Segundo o Instituto Ambiental do Paraná (2004), as águas do reservatório do Passaúna são moderadamente degradadas, com tendência moderada a eutrofização.

\footnotetext{
1 Universidade Federal do Paraná, Departamento de Botânica, Curitiba, PR, Brasil

2 Universidade Federal do Rio Grande do Sul, Departamento de Botânica, Programa de Pós-Graduação em Botânica, Porto Alegre, RS, Brasil

3 Autor para correspondência: lucielle.bertolli@gmail.com
} 
Partes do caule de Polygonum hydropiperoides Michaux (Polygonaceae) foram coletadas em um banco da macrófita a aproximadamente $300 \mathrm{~m}$ da barragem do reservatório $\left(49^{\circ} 23^{\prime} 13^{\prime \prime} \mathrm{W}, 25^{\circ} 31^{\prime} 57^{\prime \prime} \mathrm{S}\right)$. As coletas foram realizadas em quatro expedições, entre outubro de 2007 e agosto de 2008 (Tabela 1). As amostras foram acondicionadas em frascos com solução Transeau e registradas no Herbário da Universidade Federal do Paraná (UPCB). Para a remoção do material perifítico foram utilizados jatos de água destilada e lâmina de barbear envolta por papel alumínio.

O material perifítico removido foi oxidado pelo o método de Simonsen (1974) modificado por Moreira-Filho \& Valente-Moreira (1981) para a confecção de lâminas permanentes. As diatomáceas foram observadas em microscópio fotônico binocular Olympus CH-2 e o registro fotográfico dos táxons através câmera Olympus DP71 acoplada a microscópio Olympus BX40. Adicionalmente, foram preparados suportes metálicos com amostras oxidadas, metalizados com ouro em aparelho Balzers SCD030, para visualização em microscópio eletrônico de varredura (MEV) Jeol 6360LV.

A determinação taxonômica baseou-se em literatura clássica e recente, como Krammer \& Lange-Bertalot (1986, 1988, 1991a, 1991b), Metzeltin \& Lange-Bertalot $(1998,2007)$, Metzeltin et al. (2005), Jahn et al. (2001) Krammer (1992, 1997a,b, 2000, 2002, 2003) Lange-Bertalot (1993). Dados morfométricos e merísticos foram providenciados para todos os táxons (Tabela 2).

A indicação de primeiro registro de táxons para o Estado foi baseada em Tremarin et al. (2009b). Estes táxons foram descritos utilizando-se terminologia baseada em Barber \& Haworth (1981), Hendey (1964) e Round et al. (1990).

\section{Resultados e discussão}

Um total de 106 táxons de diatomáceas foi determinado, dos quais 100 foram identificados em nível infragenérico e 15 constituíram primeiras citações para o Estado do Paraná.

Os táxons distribuíram-se em 39 gêneros, enquadrados em 26 famílias e cerca de $81 \%$ dos mesmos pertencem à classe Bacillariophyceae, a qual inclui representantes com rafe, estrutura responsável pela secreção de mucilagem, que promove a adesão do perifíton no substrato.

A família mais representativa foi Fragilariaceae Greville, com sete gêneros caracterizados pela presença de campo de poros apical ou rimopórtulas, responsáveis também pela liberação mucilagem (Round et al. 1990). Os gêneros mais representativos em termos de riqueza de táxons foram $\mathrm{Na}$ vicula Bory (13 espécies), Gomphonema Ehrenberg (nove espécies e uma variedade) e Nitzschia Hassall (sete espécies e três variedades). Estes gêneros estão entre os cinco com maior riqueza de táxons no estado paranaense (Tremarin et al. 2009b). Os limites métricos, merísticos e a ocorrência dos táxons nas amostras constam na Tabela 2.

Vinte e seis táxons ocorreram em todas as amostras, correspondendo a aproximadamente $24 \%$ do total. A amostra de agosto apresentou a maior riqueza taxonômica (79), seguida pelas de fevereiro, de maio ( 55 e 54 táxons respectivamente) e de outubro (47 táxons). Em agosto, 27 táxons ocorreram apenas nesta estação, o que originou a elevada riqueza de táxons neste mês.

Seguem as descrições, obra original, basiônimo e comentários acerca dos táxons registrados pela primeira vez no Paraná, bem como comentários sobre outros táxons considerados relevantes.

\section{Espécies registradas pela primeira vez para o estado do Paraná}

1. Discostella stelligeroides (Hustedt) Houk \& Klee, Diat. Res. 19(2): 203-228, 2004.

Basiônimo: Cyclotella stelligeroides Hustedt, Arch. Hydrobiol. 40: 899, pl. 42, fig. 68-69, 1945.

Fig. 3, 127

Valvas circulares, superfície valvar plana. Estrias marginais radiadas, regularmente encurtadas, algumas mais curtas que as adjacentes (Fig. 3). Área central com estrias dispostas em forma de roseta em torno de um poro central, às vezes pouco evidente. Em MEV, é possível distinguir um anel de fultopórtulas e uma rimopórtula marginais (Fig. 127).

Comentário: os indivíduos de D. stelligeroides são bastante semelhantes aos de D. stelligera (Cleve \& Grunow) Houk \& Klee, que se caracteriza pelas estrias marginais de igual comprimento e pela ornamentação evidente formada pelas estrias dispostas em forma de roseta em torno do poro central.

2. Punctastriata mimetica Morales, Phycol. Res. 53: 128, fig. 59-73, 115-120, 2005.

Fig. 16-18, 128-131

Valvas rombo-lanceoladas a rômbicas, extremidades arredondadas, área axial linear, área central ausente, estrias paralelas e robustas dispostas de maneira alternada (Figs. 16-18), Em MEV, é possível observar que as estrias são formadas por números variáveis de fileiras de aréolas, que convergem para uma fileira única em direção à área axial e ao manto (Fig. 128). As aréolas variam de arredondadas a levemente lineoladas. As interestrias são elevadas em relação à superfície valvar e apresentam espinhos marginais bifurcados que possibilitam a formação de cadeias (Fig. 129).

Tabela 1. Datas de coleta, coletores e número de registro das amostras utilizadas no Herbário da Universidade Federal do Paraná (UPCB).

\begin{tabular}{|c|c|c|c|}
\hline Data de coleta & Localidade & Coletores & Número de registro \\
\hline $31 / \mathrm{X} / 2007$ & Brasil. Paraná: Araucária, reservatório do rio Passaúna & Silva, A. M., Ludwig, T. A. V. & UPCB 65800 \\
\hline $20 / \mathrm{II} / 2008$ & Brasil. Paraná: Araucária, reservatório do rio Passaúna & Bertolli, L. M., Ludwig, T. A. V. & UPCB 65802 \\
\hline $02 / \mathrm{V} / 2008$ & Brasil. Paraná: Araucária, reservatório do rio Passaúna & Bertolli, L. M., Ludwig, T. A. V. & UPCB 65804 \\
\hline 27/VIII/2008 & Brasil. Paraná: Araucária, reservatório do rio Passaúna & Bertolli, L. M., Ludwig, T. A. V. & UPCB 65806 \\
\hline
\end{tabular}




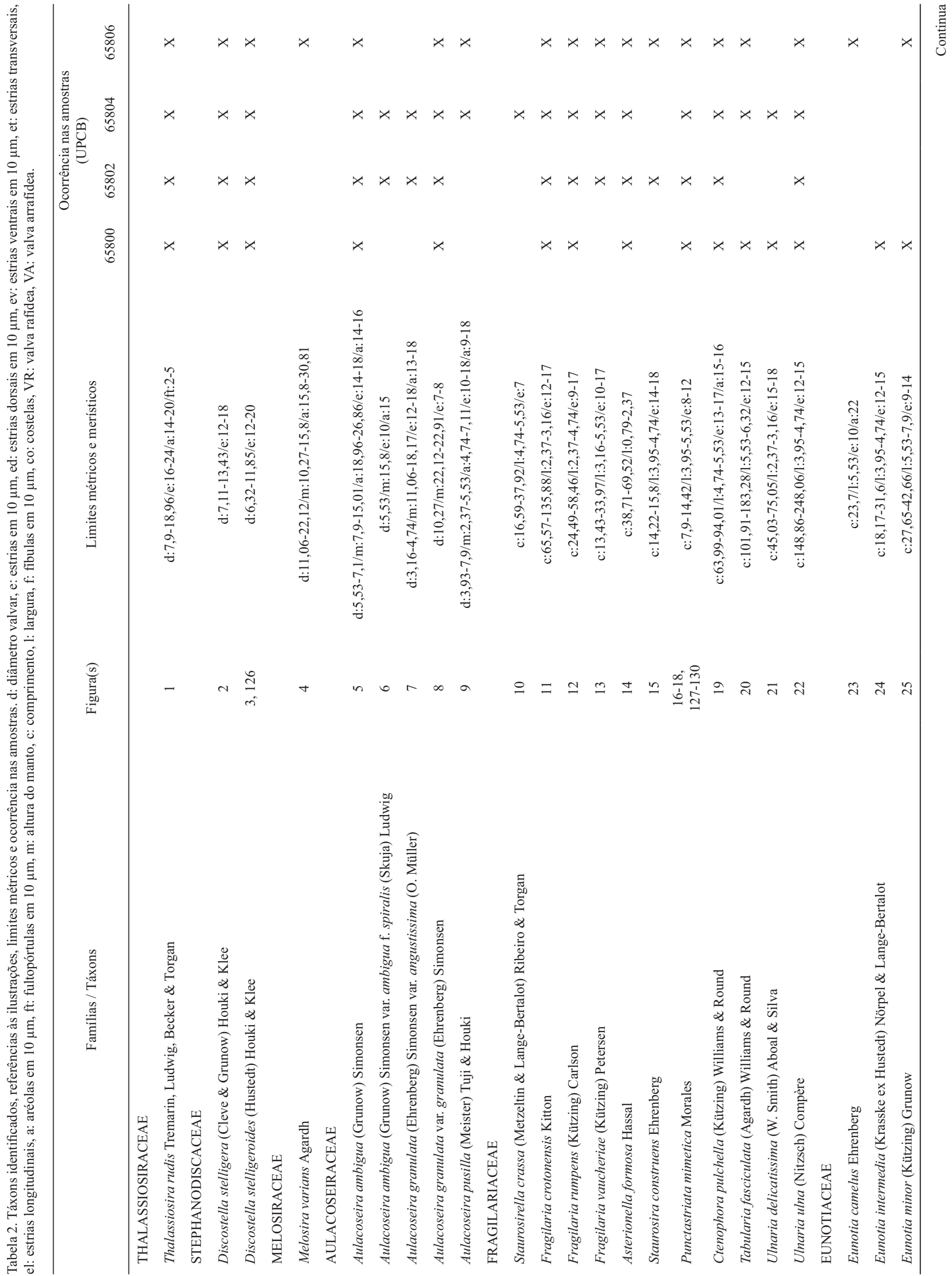




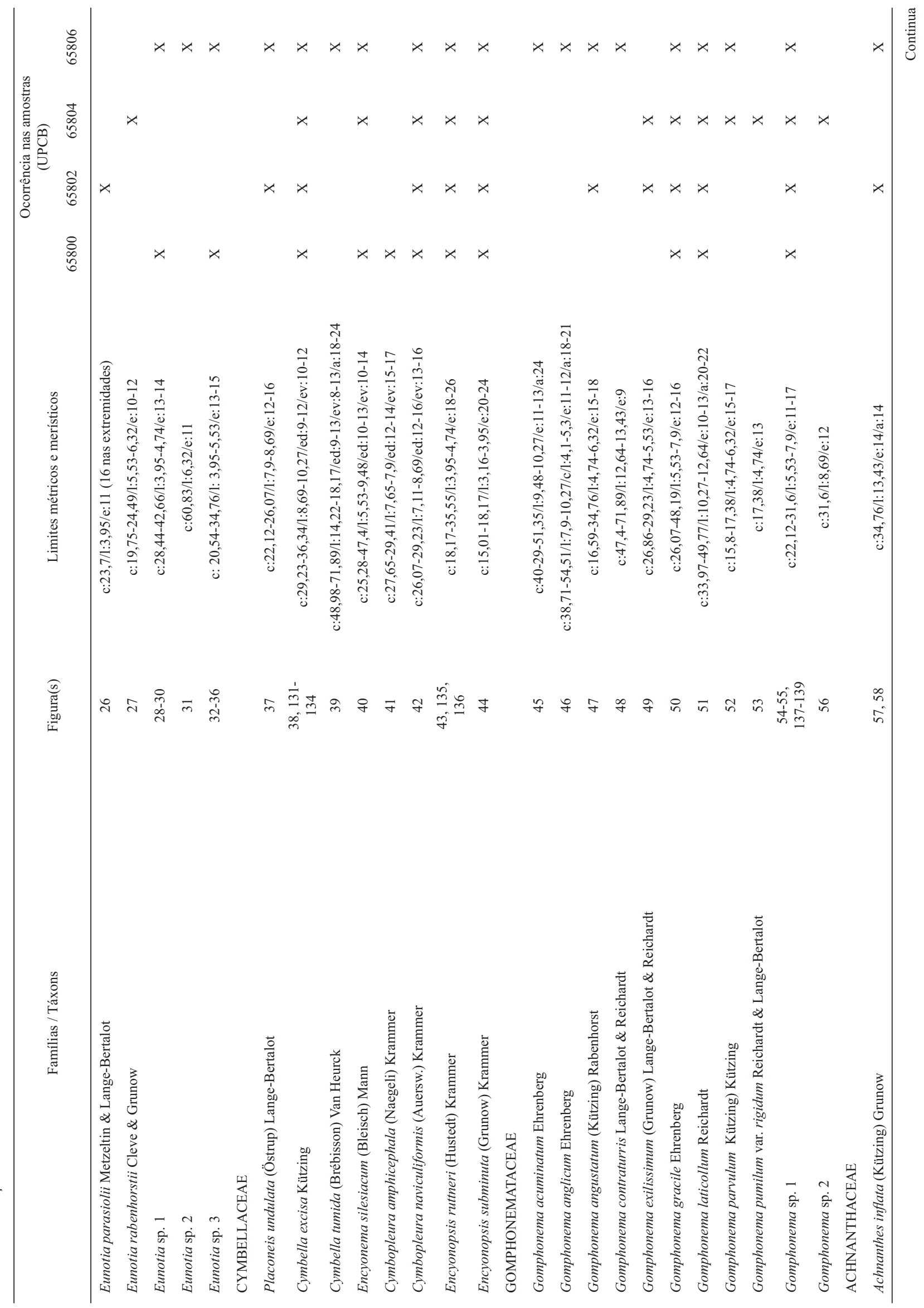




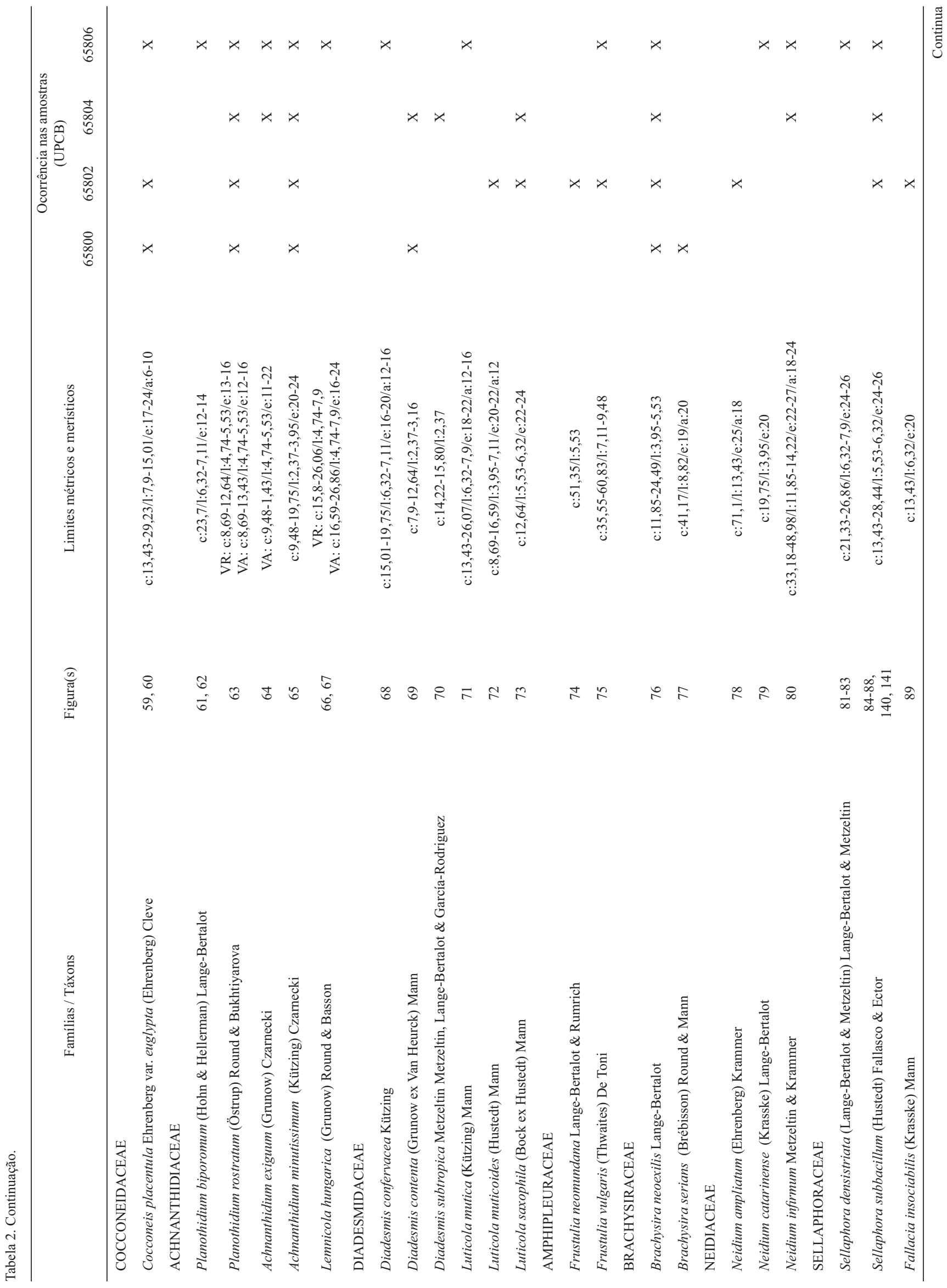


Bertolli et al.: Diatomáceas perifíticas em Polygonum hydropiperoides Michaux, reservatório do Passaúna...

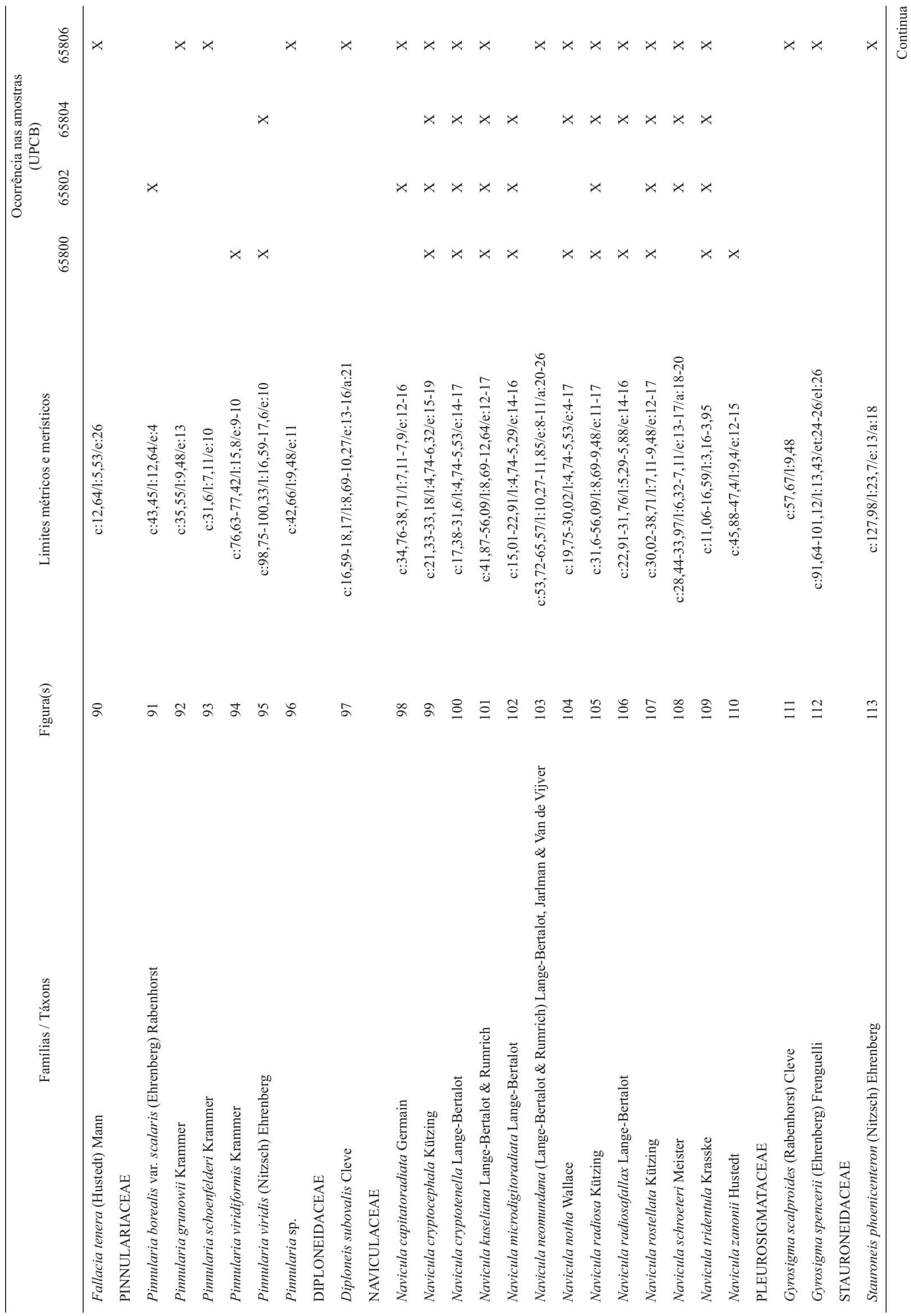




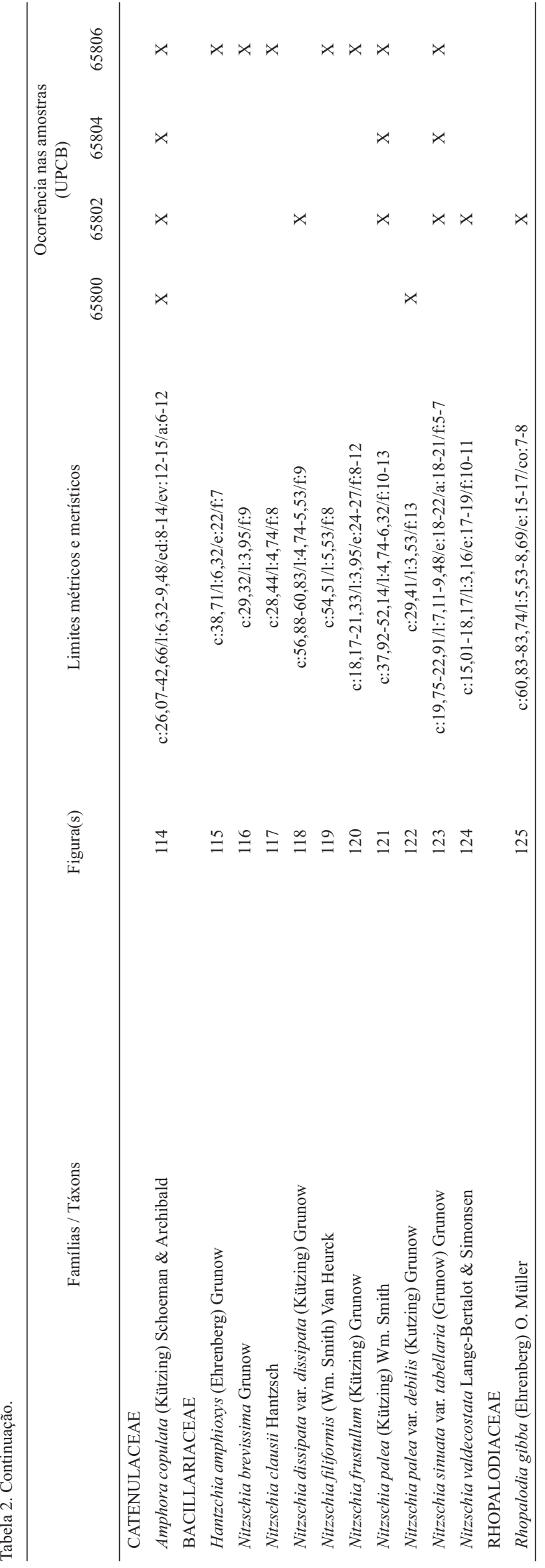

Ambas as extremidades valvares apresentam um pequeno campo de poros (Fig. 130).

Comentário: em microscopia óptica, a espécie é muito semelhante à Staurosirella pinnata (Ehrenberg) Williams \& Round, entretanto, é possível distingui-las em MEV pelo padrão de areolação, uma vez que $S$. pinnata apresenta estrias unisseriadas com aréolas alongadas apicalmente e P. mimetica apresenta estrias multisseriadas, com aréolas arredondadas (Morales 2005). A ausência de análises de materiais sob microscopia eletrônica, especialmente em trabalhos florísticos, pode ter resultado na identificação errônea de indivíduos de $P$. mimetica como $S$. pinnata, espécie frequentemente registrada no Estado (Tremarin et al. 2009b).

\section{Eunotia sp. 1}

Fig. 28-30

Valvas com margem dorsal convexa e margem ventral reta a levemente côncava, extremidades atenuado-arredondadas levemente destacadas do corpo valvar e levemente curvadas em direção à margem ventral. Nódulos terminais da rafe próximos das extremidades, estrias paralelas na região mediana a radiadas nas extremidades da valva. Comprimento: $28,44-42,66 \mu \mathrm{m}$, largura: 3,95-4,74 $\mu \mathrm{m}, 13-14$ estrias em $10 \mu \mathrm{m}$.

Comentário: o contorno valvar e o formato do ápice dos indivíduos encontrados são semelhantes ao apresentado por Metzeltin \& Lange-Bertalot (1998, pág. 351, pl. 58, fig. 5-10) como uma suposta nova espécie de Eunotia, entretanto, os indivíduos observados apresentam eixo apical menor do que o apresentado nas ilustrações dos autores citados. Também foi notada semelhança entre Eunotia sp. 1 e as ilustrações de Eunotia sudetica presentes em Frenguelli (1933, pl. 8, fig. 14-15), entretanto, embora o contorno do ápice seja semelhante nas duas espécies, E. sudetica sensu Frenguelli apresenta dimensões maiores do que o observado, e Eunotia sp. 1 apresenta maior continuidade entre corpo valvar e ápice, diferentemente da outra espécie, em que os ápices são mais destacados.

\section{Eunotia sp. 2}

Fig. 31

Valvas com margem dorsal convexa e margem ventral reta a levemente côncava, extremidades atenuado-arredondadas levemente destacadas do corpo valvar. Nódulos terminais da rafe próximos das extremidades, estrias paralelas na região mediana a radiadas nas extremidades da valva. Comprimento: 20,54-34,76 $\mu \mathrm{m}$, largura: 3,95-5,53 $\mu \mathrm{m}, 13$ 15 estrias em $10 \mu \mathrm{m}$.

Comentário: o contorno valvar e o formato do ápice dos indivíduos são semelhantes ao apresentado por Metzeltin \& Lange-Bertalot (1998, pág. 351, pl. 58, figs. 1-4) como uma suposta nova espécie de Eunotia, entretanto, não foi realizada a proposição da espécie. Também foi observada certa semelhança entre os indivíduos de Eunotia sp. 2 e de exemplares 
pequenos Eunotia luna var. aequalis Hustedt, entretanto a última apresenta extremidades menos destacados do corpo valvar (Metzeltin \& Lange-Bertalot, 1998). Os indivíduos menores são semelhantes aos determinados como Eunotia incisa Gregory por Metzeltin \& Lange-Bertalot (1998), entretanto apresentam menos estrias em $10 \mu \mathrm{m}$. Além disso, o formato dos os indivíduos classificados como $E$. incisa não corresponde ao relatado por Carter \& Flower (1988), em que o material tipo da espécie foi analisado. E. incisa apresenta margem ventral reta e extremidades agudas, formadas pelo estreitamento da valva, e os nódulos terminais da rafe encontram-se mais afastados das extremidades do que o observado em Eunotia sp. 2. Diferentemente de Eunotia sp. 1 as extremidades de Eunotia sp. 2 não apresentam curvatura em direção à margem ventral.

\section{Eunotia sp. 3}

Fig. 32-36

Valvas com margem dorsal convexa e margem ventral reta a levemente côncava, extremidades atenuado-arredondadas. Nódulos terminais da rafe próximos das extremidades, estrias radiadas em toda a extensão da valva. Comprimento: $60,83 \mu \mathrm{m}$, lrgura: $6,32 \mu \mathrm{m}, 11$ estrias em $10 \mu \mathrm{m}$..

Comentário: foi observada semelhança entre Eunotia sp. 3 e de Eunotia distinguenda Metzeltin \& Lange-Bertalot, entretanto o exemplar observado apresentou eixo transapical maior, nódulo terminal da rafe mais próximo à extremidade e extremidades menos destacadas do que o observado em E. distinguenda (Metzeltin \& Lange-Bertalot 1998). Eunotia sp. 3 também é semelhante a exemplares de Eunotia flexuosa (Brébisson) Kützing ilustrados por Krammer \& Lange-Bertalot (1991, p. 511, pl. 140, figs. 8-10), entretanto o espécime observado apresentou curvatura na valva não compatível com o registrado para E. flexuosa. A mesma constatação pode ser feita na comparação entre Eunotia sp. 3 e Eunotia dacostae Metzeltin \& Lange-Bertalot. Além da curvatura pouco pronunciada, E. dacostae apresenta dimensões maiores, estrias mais próximas entre si e o nódulo terminal encontra-se pouco deslocado da extremidade.

6. Encyonopsis ruttneri (Hustedt) Krammer, Biblioth. Diatomol. 37(2): 106, pl. 149, fig. 20-27, pl. 151, fig. 8 , 9, 18-20, 1997.

Basônimo: Cymbella ruttneri Hustedt in A. Schmidt, Atl. Diatom., pl. 373-376, 1931.

Fig. 43, 136, 137

Valvas lanceoladas, levemente dorsiventrais. Extremidades atenuado-arredondadas. Área axial linear, área central ausente, rafe levemente arqueada na região central, estrias paralelas a levemente radiadas em toda a extensão da valva, aréolas inconspícuas, estigmóide ausente. Em MEV é possível observar que as estrias são formadas por uma série de aréolas expandidas apicalmente, podendo ocorrer algumas aréolas expandidas em outros sentidos. Intermissio ausente.
Ambas as extremidades distais da rafe são expandidas internamente em pequenas helictoglossas (Fig. 137).

Comentário: Cymbella ruttneri chegou a ser considerada como sinonímia de Cymbella microcephala Grunow (Krammer \& Lange-Bertalot, 1986), entretanto, na época, as circunscrições dos táxons eram mais amplas do que o aceito na taxonomia atual, e, por isso, Krammer (1997) sugere que sinonimizações antigas sejam revistas.

7. Gomphonema pumilum var. rigidum Reichardt \& LangeBertalot in Reichardt, Nova Hedwigia 65: 105; pl. 1, fig.

7, pl. 3, fig. 1-41, pl. 4, fig. 24-25, 1997.

Fig. 53

Valvas clavadas, com pólo superior arredondado e inferior atenuado. Área axial linear, área central retangular, estigma presente. Rafe reta com extremidades proximais dilatadas em poros, levemente fletidas para o lado do estigma. Estrias radiadas em toda a extensão da valva, areolação inconspícua.

Comentário: segundo Reichardt (1997), o táxon difere da variedade típica por apresentar contorno valvar mais linear a linear-lanceolado, pela área axial mais estreita e pela área central expandida transapicalmente, retangular.

\section{Gomphonema sp. 1}

Fig. 54, 55, 137-139

Valvas lanceoladas, com pólos superior e inferior arredondados. Área axial amplamente lanceolada delimitada pelo encurtamento regular das estrias, área central ausente, estigma presente. Rafe levemente sinuosa com extremidades proximais dilatadas em poros, fletidas para o lado do estigma. Estrias radiadas em toda a extensão da valva, areolação inconspícua. Em MEV, é possível observar que as estrias são formadas por uma fileira de aréolas com formato de meia lua, o estigma apresenta abertura externa arredondada e a área axial é ornamentada por pequenas depressões.

Comentário: foi comum o registro de exemplares com deformações no ápice e/ou na base. Os exemplares observados remetem a espécies como Gomphonema clevei Fricke, G. brasiliense Grunow e G. brasiliensoide Metzeltin, LangeBertalot \& García-Rodríguez, entretanto, algumas diferenças podem ser ressaltadas. A área axial, amplamente lanceolada nas espécies citadas, é mais estreita em Gomphonema sp. 1, pois é delimitada por estrias mais alongadas. G. brasiliense e G. brasiliensoide não possuem estigma e apresentam terminação proximal da rafe simples (Moser et al. 1995, Metzeltin et al. 2005), diferentemente de Gomphonema sp. 1 , que possui estigma e apresenta terminação proximal da rafe em poro (Fig. 139). Gomphonema brasiliensoide apresenta estrias bisseriadas, formadas por aréolas alongadas apicalmente (Metzeltin et al. 2005), enquanto G. brasiliense e Gomphonema sp. 1 apresentam estrias unisseriadas formadas por aréolas em forma de meia lua (Fig. 140) (Moser et al. 1995). 

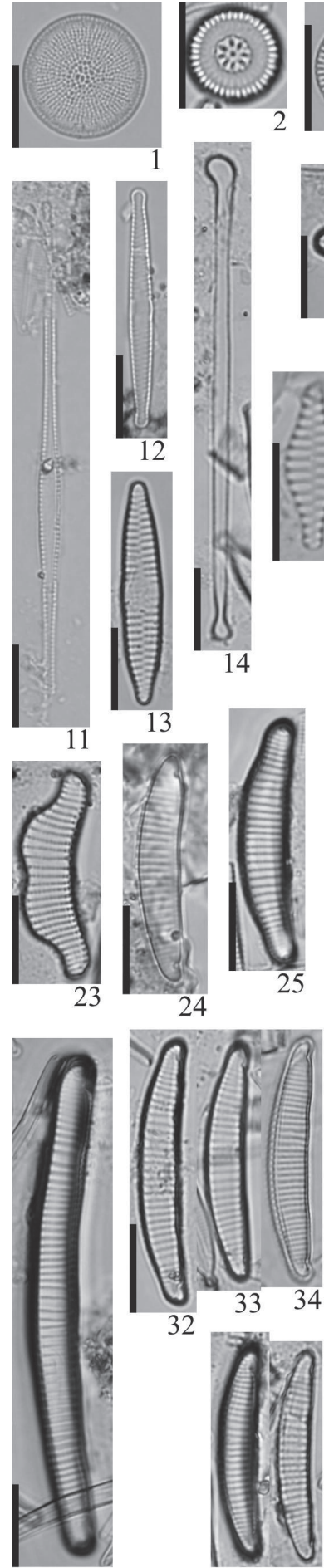

31

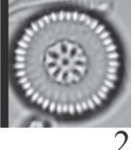

$35 \quad 36$
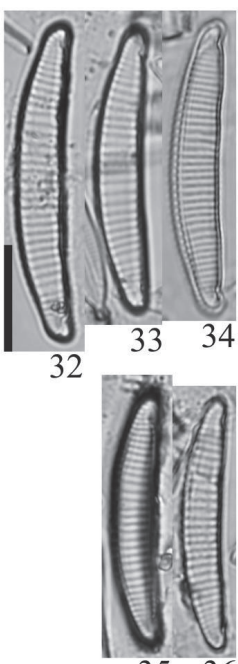

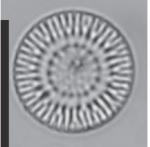

3

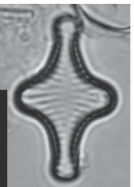

15

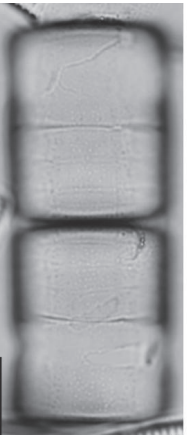

4
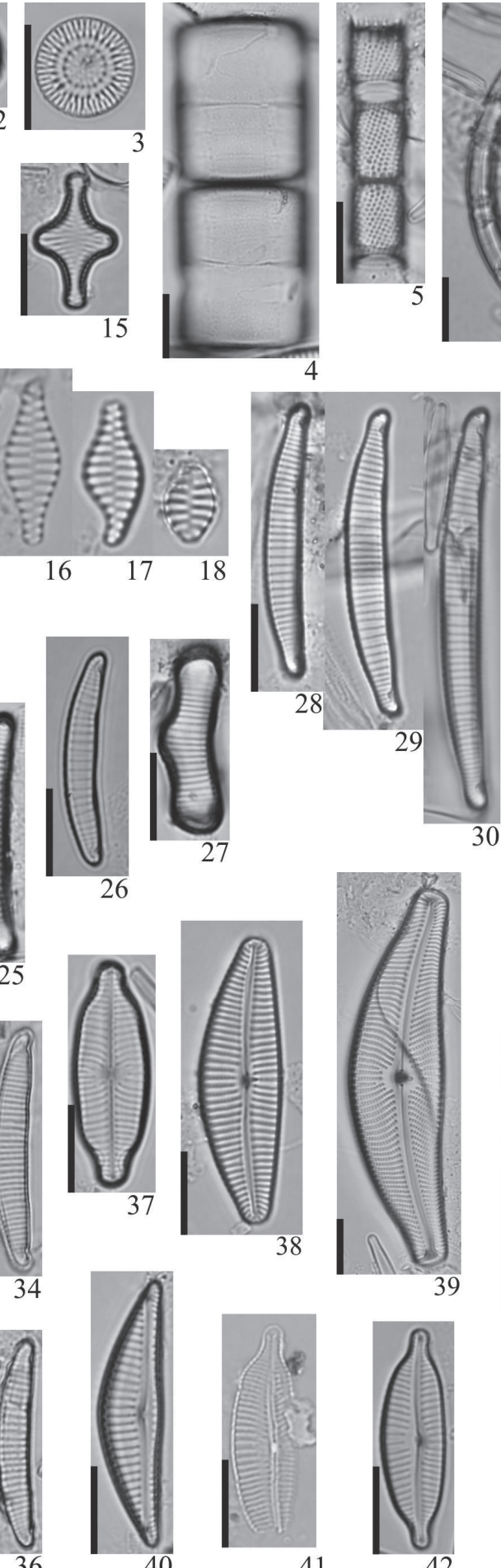

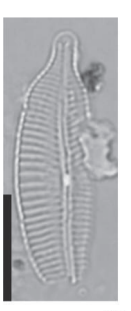

41
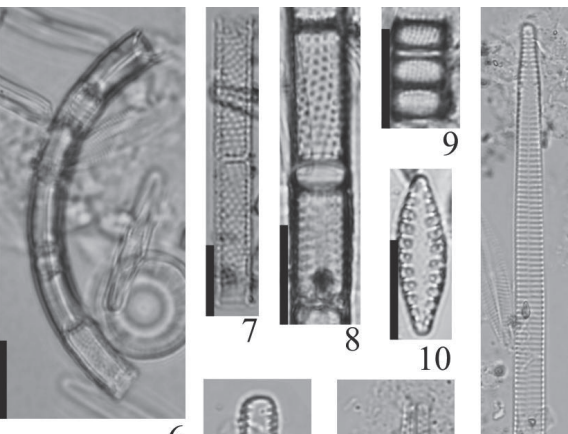

6
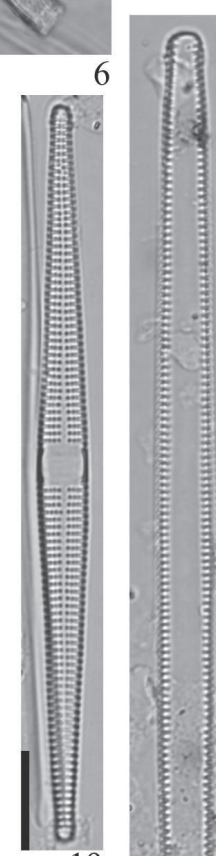

19
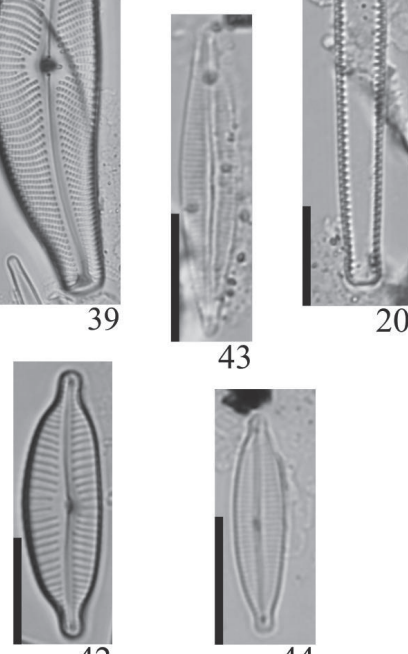

43

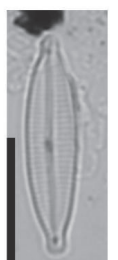

44
9

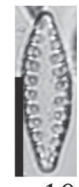

10

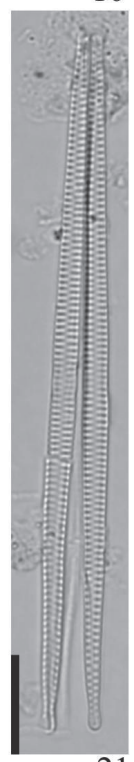

21
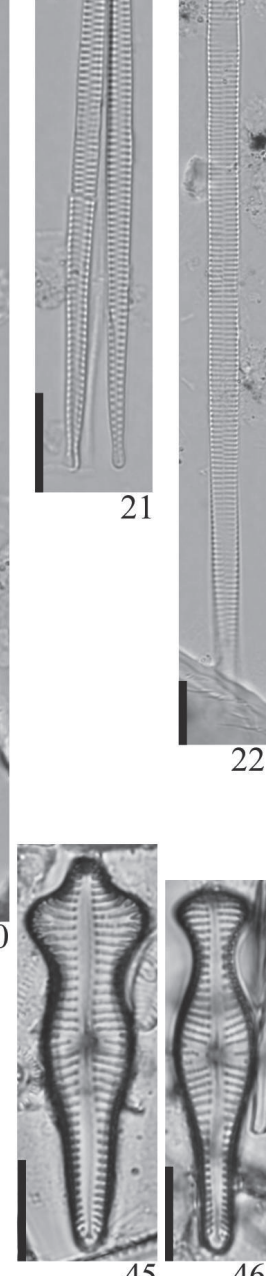

46

Figura 1-46. Diatomáceas perifíticas. 1. Thalassiosira rudis Tremarin, Ludwig, Becker \& Torgan. 2. Discostella stelligera (Cleve \& Grunow) Houk \& Klee. 3. Discostella stelligeroides (Hustedt) Houk \& Klee. 4. Melosira varians Agardh 5. Aulacoseira ambigua (Grunow) Simonsen. 6. Aulacoseira ambigua (Grunow) Simonsen var. ambigua f. spiralis (Skuja) Ludwig. 7. Aulacoseira granulata (Ehrenberg) Simonsen var. angustissima (O. Müller). 8. Aulacoseira granulata var. granulata (Ehrenberg) Simonsen. 9. Aulacoseira pusilla (Meister) Tuji \& Houki. 10. Staurosirella crassa (Metzeltin \& Lange-Bertalot) Ribeiro \& Torgan. 11. Fragilaria crotonensis Kitton. 12. Fragilaria rumpens (Kützing) Carlson. 13. Fragilaria vaucheriae (Kützing) Petersen. 14. Asterionella formosa Hassall. 15. Staurosira construens Ehrenberg. 16-18. Punctastriata mimetica Morales. 19. Ctenophora pulchella (Kützing) Williams \& Round. 20. Tabularia fasciculata (Agardh) Williams \& Round. 21. Ulnaria delicatissima (W. Smith) Aboal \& Silva. 22. Ulnaria ulna (Nitzsch) Compère. 23. Eunotia camelus Ehrenberg. 24. Eunotia intermedia (Krasske ex Hustedt) Nörpel \& Lange-Bertalot. 25. Eunotia minor (Kützing) Grunow. 26. Eunotia parasiolii Metzeltin \& Lange-Bertalot. 27. Eunotia rabenhorstii Cleve \& Grunow 28. Eunotia sp. 1. 29-30. Eunotia sp. 2. 31-32. Eunotia sp. 3. 33. Eunotia sp. 4. 34. Eunotia sp. 6. 35-36. Eunotia sp. 6. 37. Placoneis undulata (Östrup) Lange-Bertalot. 38. Cymbella excisa Kützing. 39. Cymbella tumida (Brébisson) Van Heurck. 40. Encyonema silesiacum (Bleisch) Mann. 41. Cymbopleura amphicephala (Naegeli) Krammer. 42. Cymbopleura naviculiformis (Auerswald) Krammer. 43. Encyonopsis ruttneri (Hustedt) Krammer. 44. Encyonopsis subminuta (Grunow) Krammer. 45. Gomphonema acuminatum Ehrenberg. 46. Gomphonema anglicum Ehrenberg. 

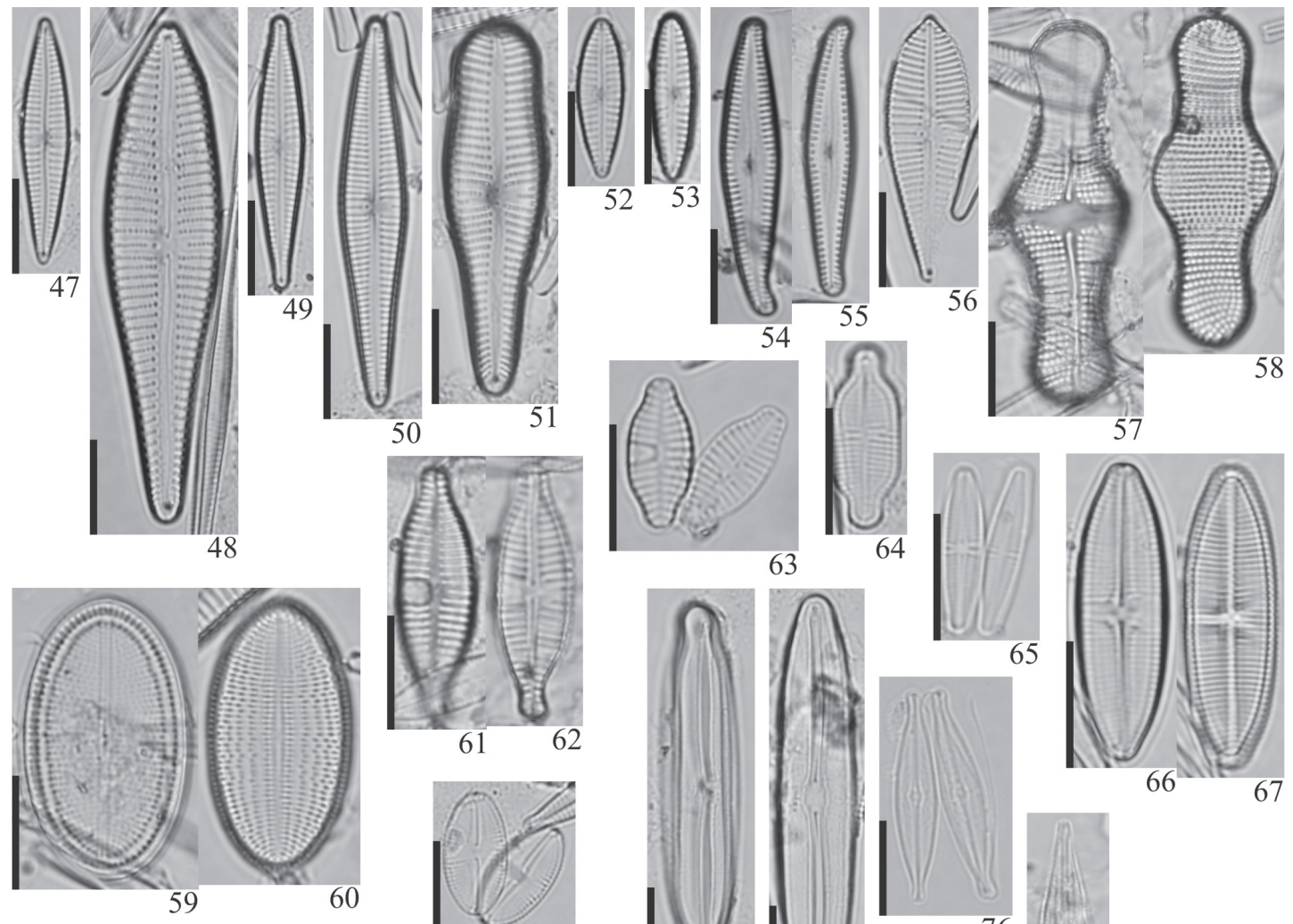

64
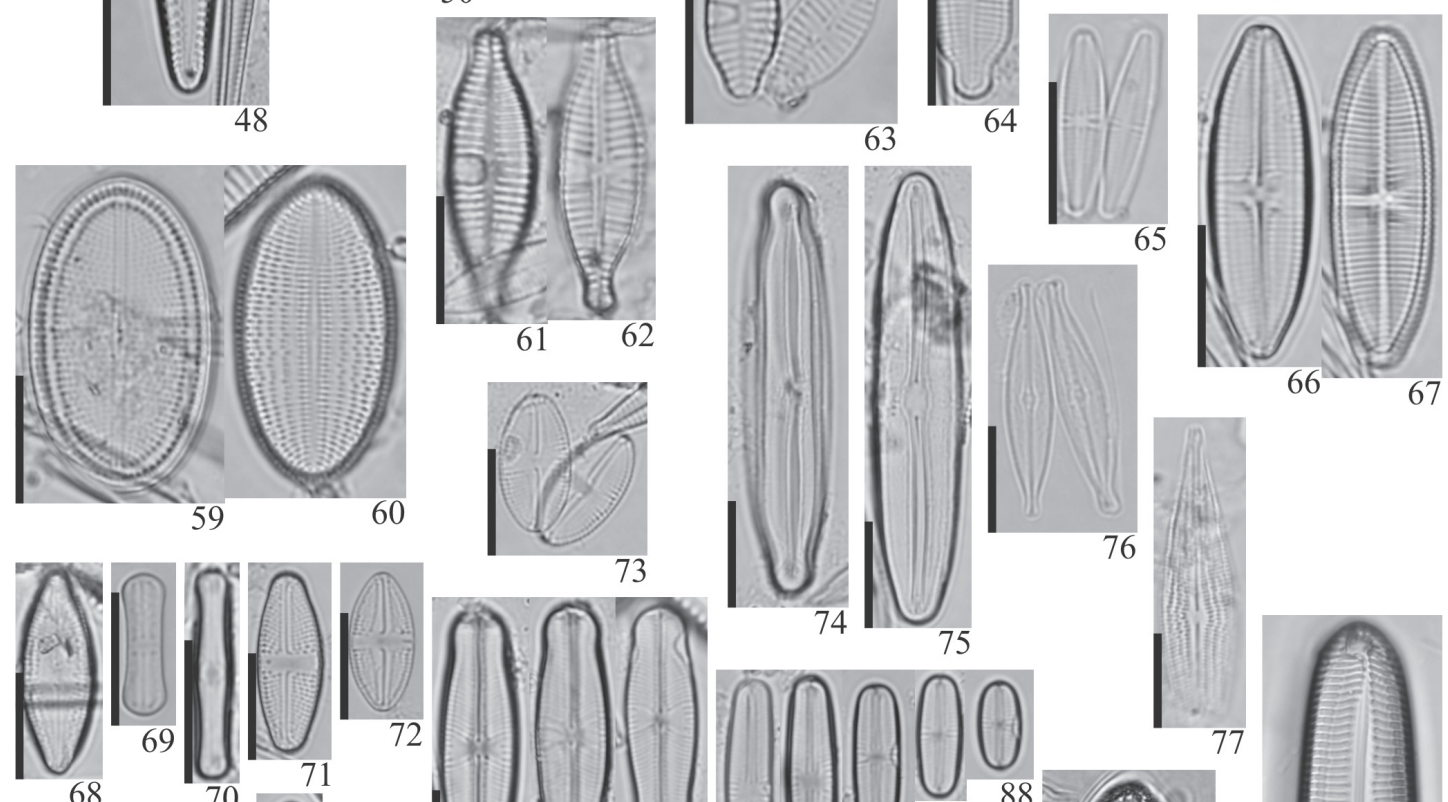

68

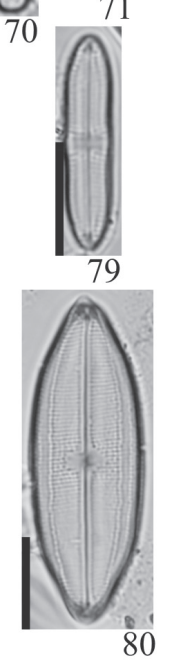

.
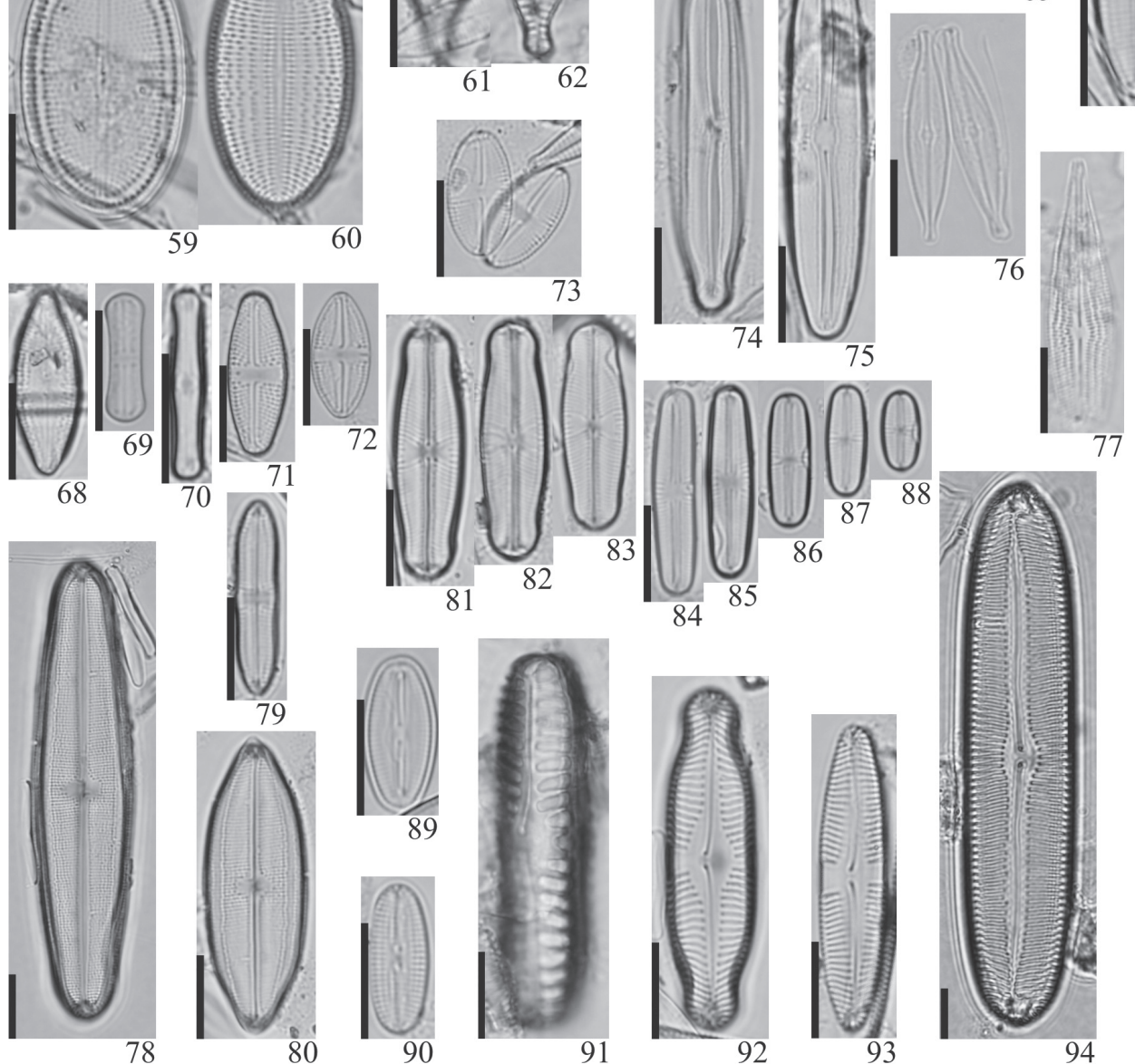

Figura 47-95. Diatomáceas perifíticas. 47. Gomphonema angustatum (Kützing) Rabenhorst. 48. Gomphonema contraturris Lange-Bertalot \& Reichardt. 49. Gomphonema exilissimum (Grunow) Lange-Bertalot \& Reichardt. 50. Gomphonema gracile Ehrenberg. 51. Gomphonema laticollum Reichardt. 52. Gomphonema parvulum (Kützing) Kützing. 53. Gomphonema pumilum var. rigidum Reichardt \& Lange-Bertalot. 54-55. Gomphonema sp. 1. 56. Gomphonema sp. 2. 57-58. Achnanthes inflata (Kützing) Grunow. 59-60. Cocconeis placentula Ehrenberg var. euglypta (Ehrenberg) Cleve. 61-62. Planothidium biporomum (Hohn \& Hellerman) LangeBertalot. 63. Planothidium rostratum (Östrup) Round \& Bukhtiyarova. 64. Achnanthidium exiguum (Grunow) Czarnecki. 65. Achnanthidium minutissimum (Kützing) Czarnecki. 66-67. Lemnicola hungarica (Grunow) Round \& Basson. 68. Diadesmis confervacea Kützing. 69. Diadesmis contenta (Grunow ex Van Heurck) Mann. 70. Diadesmis subtropica Metzeltin, Lange-Bertalot \& García-Rodriguez. 71. Luticola mutica (Kützing) Mann. 72. Luticola muticoides (Hustedt) Mann. 73. Luticola saxophila (Bock ex Hustedt) Mann. 74. Frustulia neomundana Lange-Bertalot \& Rumrich. 75. Frustulia vulgaris (Thwaites) De Toni. 76. Brachysira neoexilis LangeBertalot. 77. Brachysira serians (Brébisson) Round \& Mann. 78. Neidium ampliatum (Ehrenberg) Krammer. 79. Neidium catarinense (Krasske) Lange-Bertalot. 80 Neidium infirmum Metzeltin \& Krammer. 81-83. Sellaphora densistriata (Lange-Bertalot \& Metzeltin) Lange-Bertalot \& Metzeltin. 84-88. Sellaphora subbacillum (Hustedt) Fallasco \& Ector. 89. Fallacia insociabilis (Krasske) Mann. 90. F. monoculata (Hustedt) Mann. 91. Pinnularia borealis var. scalaris (Ehrenberg) Rabenhorst. 92. Pinnularia grunowii Krammer. 93. Pinnularia schoenfelderi Krammer. 94. Pinnularia viridiformis Krammer 95. Pinnularia viridis (Nitzsch) Ehrenberg. 


\section{Gomphonema sp. 2}

Fig. 56

Valvas heteropolares, lanceoladas, com pólo superior sub-rostrado e pólo inferior atenuado-arredondado. Área axial linear, área central unilateral, limitada pelo encurtamento de uma estria mediana, estigma no lado oposto à área central. Rafe arqueada com extremidades proximais dilatadas em poros, fletidas para o lado do estigma. Estrias radiadas em toda a extensão da valva, areolação inconspícua. Comprimento: $31,6 \mu \mathrm{m}$, largura: 8,69 $\mu \mathrm{m}, 12$ estrias em $10 \mu \mathrm{m}$.

Comentário: o indivíduo analisado é semelhante ao morfotipo 1 de Gomphonema turris var. coarctata (Frenguelli) Frenguelli, apresentado por Tremarin et al. (2009a), no entanto Gomphonema sp. 2 apresenta dimensões menores e ápices mais delicados.

10. Sellaphora densistriata (Lange-Bertalot \& Metzeltin) Lange-Bertalot \& Metzeltin in Lange-Bertalot, Iconogr. Diatomol. 11: 58, 2002.

Basônimo: Sellaphora pupula var. densistriata, Iconog. Diatomol. 2: 102, pl. 25, fig. 9, 1996.

Fig. 81-83

Valvas linear-elípticas com intumescimento na região mediana, extremidades subcapitado-arredondadas, área axial linear, área central lateralmente expandida pelo encurtamento das estrias medianas, rafe levemente arqueada, com extremidades proximais dilatadas em poros, estrias radiadas em toda a extensão da valva, mais espaçadas na região mediana.

Comentário: a espécie pode ser enquadrada no complexo Sellaphora pupula (Kützing) Mereschkowsky, determinado por Mann et al. (2008), pois apresenta área axial estreita, área central não circular, nódulo central inconspícuo e barras polares. Inicialmente o táxon foi descrito como uma variedade de S. pupula (Lange-Bertalot \& Metzeltin 1996), entretanto Metzeltin \& Lange-Bertalot (2002) optaram por elevar o status do táxon para espécie, não apenas pela maior densidade de estrias, mas também pelo ângulo de disposição das estrias e pelo contorno da valva, diferentes de S. pupula sensu stricto.

11. Sellaphora subbacillum (Hustedt) Falasco \& Ector in Falasco et al., Fottea 9(2): 251, fig. 98-107, 127-129, 2009.

Basônimo: Navicula subbacillum Hustedt, Arch. Hydrobiol. 15(2): pl. 18, fig. 3-6, 1937.

Fig. 84-88, 140, 141

Valvas linear-elípticas, extremidades arredondadas, área axial linear, área central lateralmente expandida pelo encurtamento das estrias medianas, rafe reta com extremidades proximais dilatadas em poros, estrias de difícil distinção, radiadas em toda a extensão da valva, mais espaçadas na região mediana. Em MEV, observaram-se estrias unisse- riadas, formadas por aréolas arredondadas, extremidades distais da rafe em gancho e presença de canópio envolvendo o sistema da rafe (Fig. 141). Internamente podem-se notar as terminações distais da rafe expandidas em delicadas helictoglossas (Fig. 142).

Comentários: o táxon assemelha-se ao ilustrado por Krammer \& Lange-Bertalot (1986, pl. 69, fig. 1-10) como Navicula stroemii Hustedt. Entretanto, as ilustrações referentes a esta espécie em Hustedt (1930) e em Simonsen (1987) não corroboram a determinação de Krammer \& Lange-Bertalot (1986). Falasco et al. (2009) estudaram o material tipo de $N$. stroemii e de outras seis espécies citadas como sinônimos por Krammer \& Lange-Bertalot (1986): N. subbacillum Hustedt, N. vasta Hustedt, $N$. rivularis Hustedt, $N$. subcontenta, $N$. ventraloides Hustedt e $N$. aggerica Reichardt. Com o estudo detalhado dos espécimes em microscopias fotônica e eletrônica, os autores optaram por rejeitar a sinonimização de $N$. subbacillum e $N$. vasta como $N$. stroemii, por entenderem que ambas constituem um grupo distinto, com extremidades sempre arredondadas e área central frequentemente ausente ou pequena e arredondada (diferentemente de $N$. stroemii que pode apresentar extremidades subcapitadas em indivíduos maiores e área central em forma de gravata borboleta). N. subbacillum e $N$. vasta foram sinonimizadas e transferidas para Sellaphora subbacillum (Falasco et al. 2009).

\section{Pinnularia sp.}

Fig. 96

Valvas linear-lanceoladas, extremidades arredondadas, área axial lanceolada, área central levemente elíptica, alcançando a margem de um dos lados da valva. Rafe levemente sinuosa com extremidades proximais fletidas para o lado em que área central é menos expandida e extremidades distais em forma de gancho. Estrias radiadas no centro da valva e convergentes nas extremidades.

Comentários: o formato da valva de Pinnularia sp. é semelhante ao dos exemplares pequenos de Pinnularia microstauron (Ehrenberg) Cleve ilustrados por Krammer (2000, p. 359, pl. 50, fig. 7 e 8), no entanto, os táxons diferem na amplitude da área axial (mais ampla no primeiro) e na área central (arredondada, alcançando apenas uma das margens no primeiro e retangular, alcançando ambas as margens no segundo).

13. Navicula microdigitoradiata Lange-Bertalot, Biblioth. Diatomol. 27: 123, pl. 58, fig. 9-15, pl. 59, fig. 23-24, 1993.

Fig. 102

Valvas lanceoladas, extremidades atenuado-arredondadas. Área axial linear, área central irregular, rafe reta. Estrias fortemente radiadas na região central a levemente convergentes nas extremidades, estria mediana mais longa que as adjacentes em um lado da valva e mais curta do outro lado. Aréolas inconspícuas. 

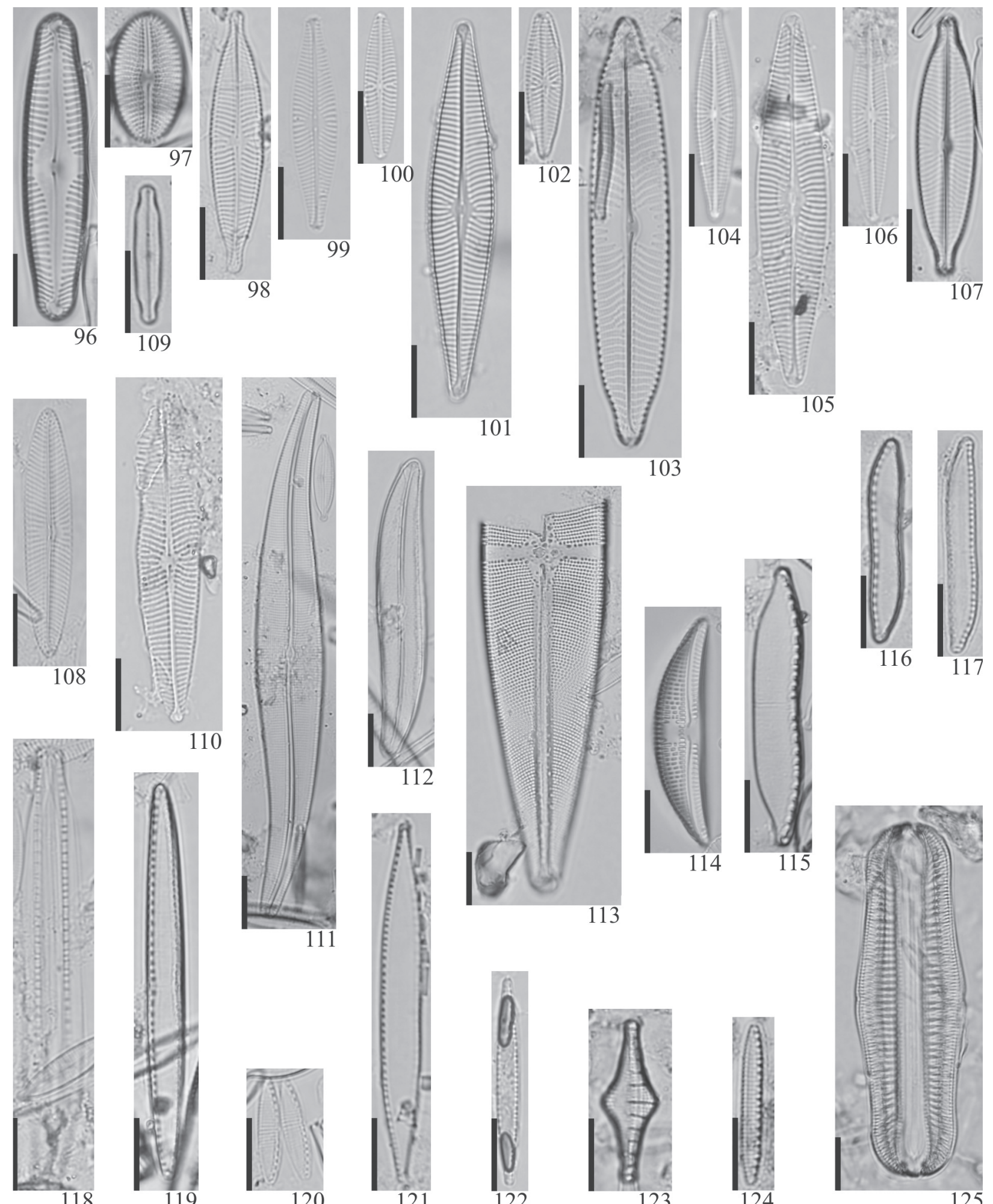

Figura 96-125. Diatomáceas perifíticas. 96. Pinnularia sp. 97. Diploneis subovalis Cleve. 98. Navicula capitatoradiata Germain. 99. Navicula cryptocephala Kützing. 100. Navicula cryptotenella Lange-Bertalot. 101. Navicula kuseliana Lange-Bertalot \& Rumrich. 102. Navicula microdigitoradiata Lange-Bertalot. 103. Navicula neomundana (Lange-Bertalot \& Rumrich) Lange-Bertalot, Jarlman \& Van de Vijver. 104. Navicula notha Wallace. 105. Navicula radiosa Kützing. 106. Navicula radiosafallax Lange-Bertalot. 107. Navicula rostellata Kützing. 108. Navicula schroeteri Meister. 109. Navicula tridentula Krasske. 110. Navicula zanonii Hustedt. 111. Gyrosigma scalproides (Rabenhorst) Cleve. 112. Gyrosigma spencerii (Ehrenberg) Frenguelli. 113. Stauroneis phoenicenteron (Nitzsch) Ehrenberg. 114. Amphora copulata (Kützing) Schoeman \& Archibald. 115. Hantzchia amphioxys (Ehrenberg) Grunow. 116. Nitzschia brevissima Grunow 117. Nitzschia clausii Hantzsch 118. Nitzschia dissipata var. dissipata (Kützing) Grunow. 119. Nitzschia filiformis (W. Smith) Van Heurck. 120. Nitzschia frustullum (Kützing) Grunow. 121. Nitzschia palea (Kützing) W. Smith. 122. Nitzschia palea var. debilis (Kützing) Grunow. 123. Nitzschia sinuata var. tabellaria (Grunow) Grunow. 124. Nitzschia valdecostata Lange-Bertalot \& Simonsen. 125. Rhopalodia gibba (Ehrenberg) O. Müller. 


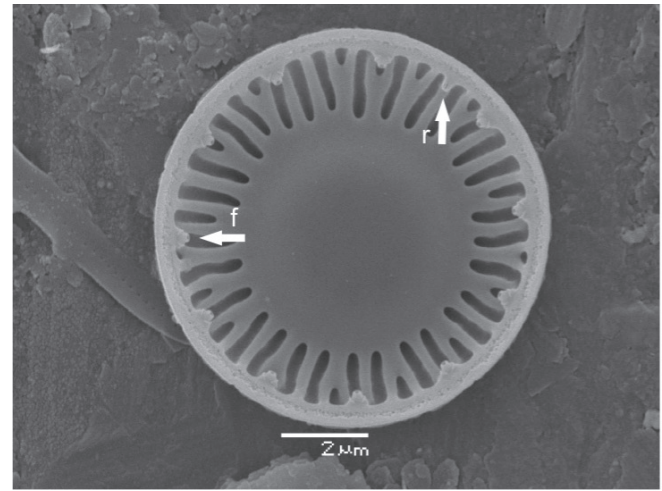

126

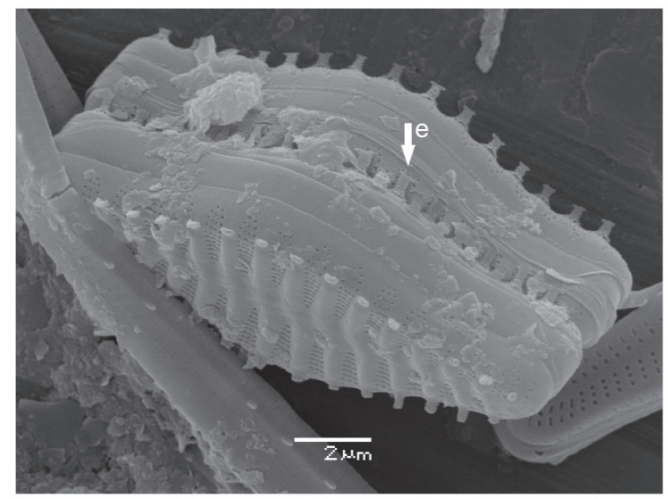

128

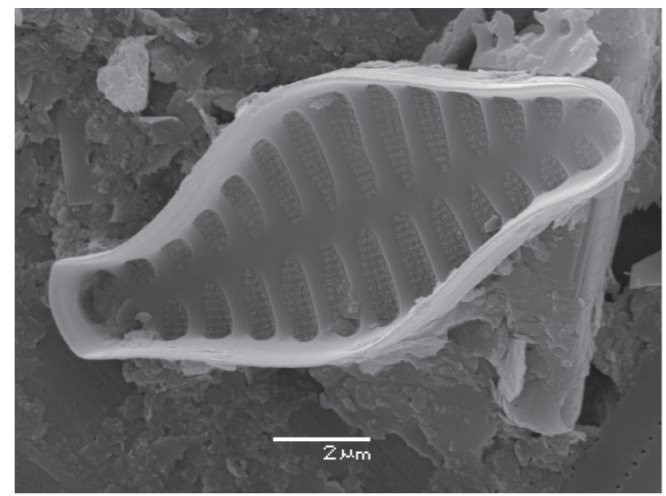

130

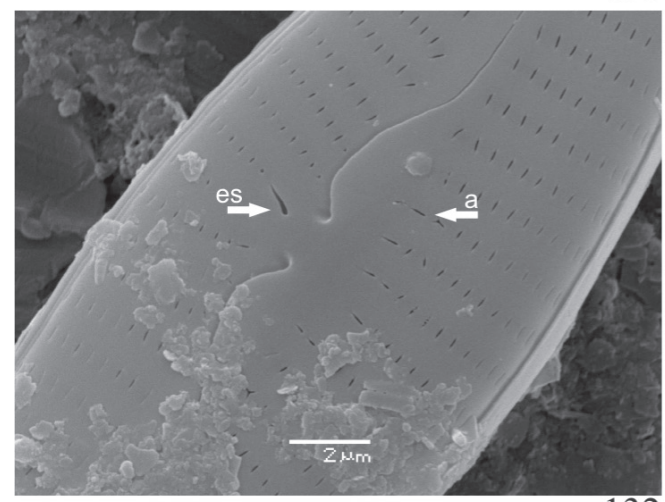

132

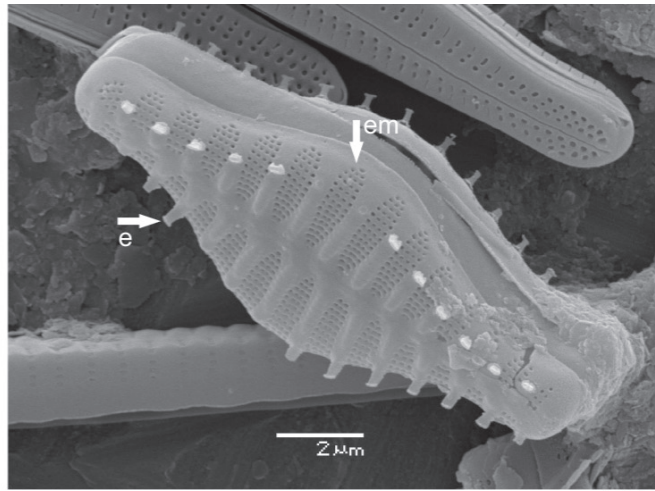

127

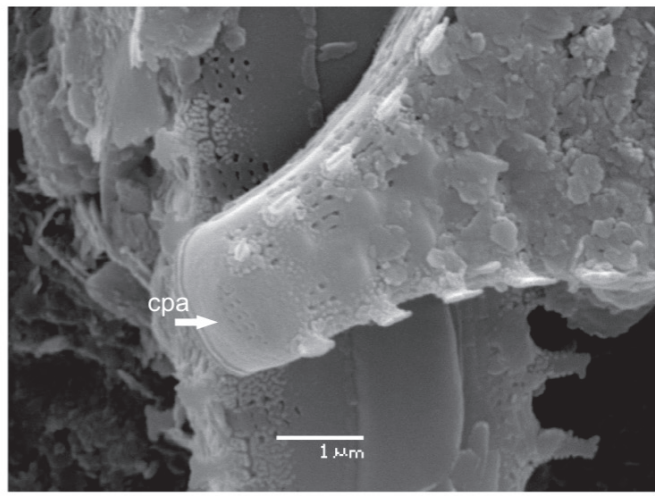

129

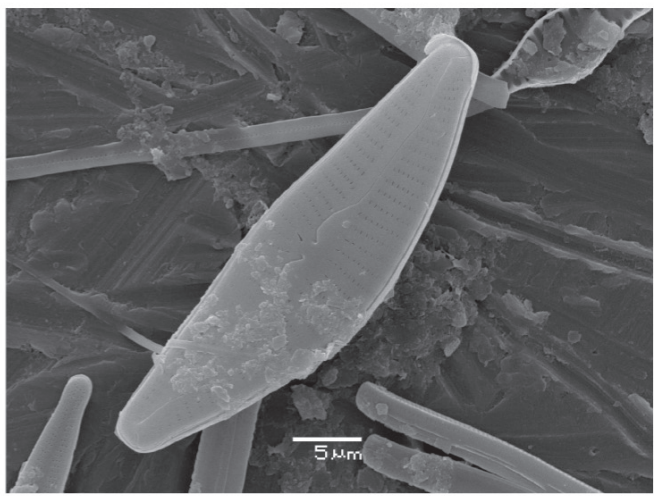

131

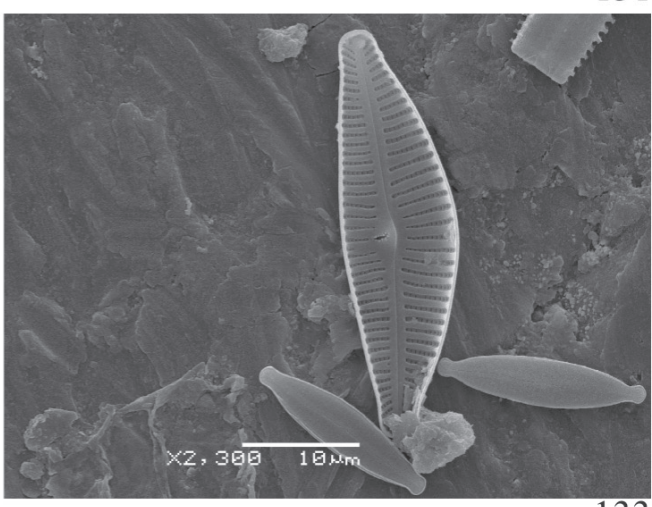

133

Figura 126-133. Diatomáceas perifíticas. 126. Discostella stelligeroides (Hustedt) Houk \& Klee. Vista interna. Fultopórtulas (f) formando um anel marginal e rimopórtulas destacadas. 127. Punctastriata mimetica Morales. Vista externa. Espinhos (e) e estrias multisseriadas (em) em destaque. 128. Punctastriata mimetica Morales. Vista externa. Frústulas unidas por espinhos conectores (e). 129. Punctastriata mimetica Morales. Vista externa. Detalhe do campo de poros apical (cpa) em uma das extremidades. 130. Punctastriata mimetica Morales. Vista geral interna. 131. Cymbella excisa Kützing. Vista geral externa. 132. Cymbella excisa Kützing. Vista externa. Região mediana da valva, com estigma (es) com abertura em fenda e aréolas (a) expandidas transapicalmente próximo à área central. 133. Cymbella excisa Kützing. Vista geral interna. 

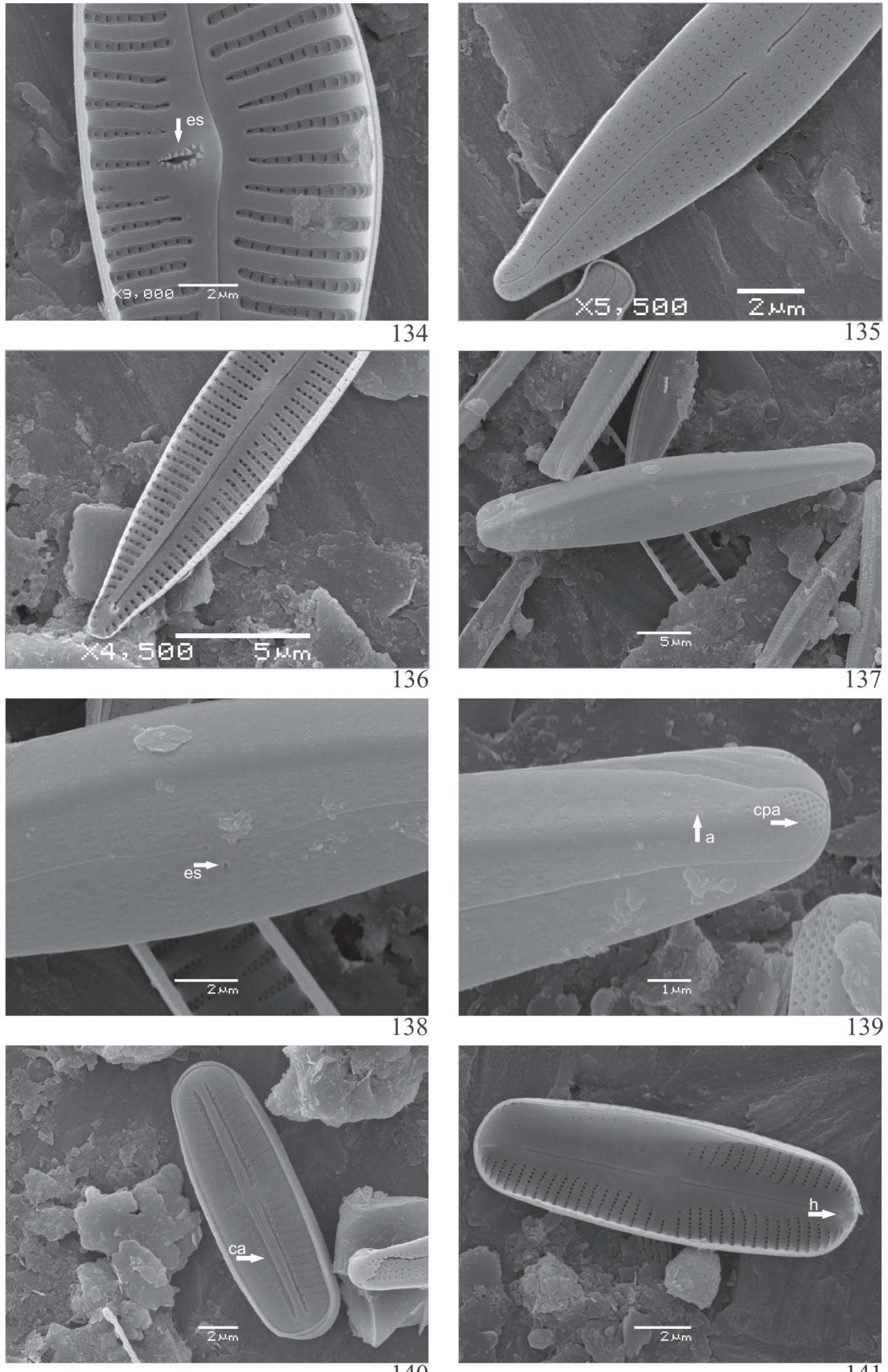

Figura 134-141. Diatomáceas perifíticas. 134. Cymbella excisa Kützing. Vista interna. Abertura do estigma (es) rodeada por estruturas semelhantes a dentes. 135. Encyonopsis ruttneri (Hustedt) Krammer. Vista geral externa. 136. Encyonopsis ruttneri (Hustedt) Krammer. Vista geral interna. Destaque para as pequenas helictoglossas (h) nas terminações distais da rafe. 137. Gomphonema sp. 1. Vista geral externa. 138. Gomphonema sp. 1. Vista externa. Detalhe da região mediana e do estigma (e). 139. Gomphonema sp. 1. Vista externa. Detalhe da base. Destaque para o campo de poros apical (cpa) e para as aréolas em forma de meia lua (a). 140. Sellaphora subbacillum (Hustedt) Fallasco \& Ector. Vista externa. Destaque para o canópio (ca) ladeando a rafe. 141. Sellaphora subbacillum (Hustedt) Falasco \& Ector. Vista interna. Destaque para a pequena helictoglossa (h) na terminação distal da rafe. 
Comentário: o táxon é bastante semelhante à Navicula digitoradiata (Gregory) Ralfs, entretanto as dimensões dos táxons são diferentes, em $N$. digitoradiata o comprimento de varia de 25 a $80 \mu \mathrm{m}$ e a largura de 7 a $28 \mu \mathrm{m}$ (Krammer $\&$ Lange-Bertalot, 1986) enquanto que em $N$. microdigitoradiata estas dimensões variam entre 15 e $40 \mu \mathrm{m}$ e 5 e 7 $\mu \mathrm{m}$, respectivamente (Lange-Bertalot 1993).

14. Navicula neomundana (Lange-Bertalot \& Rumrich) Lange-Bertalot, Jarlman \& Van de Vijver in Van de Vijver \& Lange-Bertalot, Diat. Res. 24(2): 424, fig. 87-95, 2009.

Basiônimo: Navicula viridulacalcis ssp. neomundana Lange-Bertalot \& Rumrich In U. Rumrich, Lange-Bertalot $\&$ M. Rumrich, Iconogr. Diatomol. 9: 175, pl. 37, fig. 5-8, pl. 38, fig. 1-4, 2000.

Fig. 103

Valvas linear-lanceoladas, com extremidades cuneadoarredondadas, área axial linear, área central elíptica, formada pelo encurtamento das estrias medianas, rafe reta com extremidades proximais dilatadas em poro, fletidas para o mesmo lado, estrias grosseiras, radiadas na região mediana da valva e paralelas a convergentes em direção as extremidades, aréolas lineoladas grosseiras.

Comentário: o táxon é semelhante ao complexo Navicula viridula, que inclui as variedades desta espécie e outros táxons semelhantes. No entanto, o nódulo central não é tão espessado e as extremidades proximais da rafe não são fortemente fletidas (Rumrich et al. 2000).

15. Nitzschia valdecostata Lange-Bertalot \& Simonsen, Bacill. 1: 58, fig. 260-263, 269, 270, 1978.

Fig. 124

Valvas lineares com extremidades arredondadas, fíbulas marginais não equidistantes entre si, estrias grosseiras, paralelas a levemente radiadas, aréolas arredondadas.

Comentário: Lange-Bertalot \& Simonsen (1978) comentam que a principal diferença entre $N$. valdecostata e $N$. valdestriata Aeem. \& Hustedt é a presença de um nódulo central visível tanto em microscopia fotônica quanto eletrônica, no entanto esta estrutura não pode ser visualizada nas ilustrações apresentadas pelos autores. Em microscopia fotônica, o que pode ser utilizado como caráter discriminante entre os táxons é a variação métrica e o formato das extremidades. Lange-Bertalot \& Simonsen (1978) e Krammer \& Lange-Bertalot (1988) registram $N$. valdecostata para lagos de água salina e águas com alto teor de eletrólitos. Este registro é corroborado por Maidana \& Seeligman (2006), que citam a espécie para as lagoas Blanca e Salinas Grandes, que são um lago endorreico e uma salina, respectivamente. No entanto, Seeligman et al. (2008) relatam a presença do táxon nas lagoas Ciénga Grande, Isla Grande e Del Arenal, sendo que as duas primeiras são consideradas oligohalinas e a última hiposalina pelos autores, abrangendo o espectro de ocorrência do táxon.

\section{Comentários acerca de alguns táxons já citados para} o Estado

Krammer (2002) comenta que indivíduos de Cymbella excisa Kützing têm sido frequentemente incluídos entre indivíduos de C. affinis Kützing ou C. parva (W. Smith) Kirchner. Além dos limites métricos, as principais diferenças entre estes táxons apresentadas pelo autor são a presença de dois a quatro estigmas em $C$. affinis (e não um como em $C$. excisa) e o contorno valvar característico de C. parva, mais alongado que $C$. excisa, com extremidades mais atenuadas, menos destacadas do corpo valvar. O mesmo equívoco pode ocorrer no estado do Paraná, em que $C$. affinis é frequentemente citada (Tremarin et al. 2009b). Assim como em Lozovei \& Shirata (1990), diversos estudos não publicados ilustram C. affinis com apenas um estigma, assemelhando-se mais de C. excisa.

Embora Gomphonema anglicum Ehrenberg seja morfologicamente semelhante à Gomphonema capitatum Ehrenberg, a distinção é possível devido à relação comprimento/largura, que em G. anglicum varia de 4,1-5,8 (média entre 4,8-4,9) e em G. capitatum varia de 3,1-4,6 (média entre 3,5-3,6), ou seja, o maior valor desta razão obtido para G. capitatum ainda é menor do que a média obtida para $G$. anglicum (Reichardt 2001). Moreira-Filho et al. (1973, pl. 1, fig. 1) ilustram Gomphonema constrictum Ehrenberg, atualmente sinônimo de G. truncatum, entretanto o contorno valvar e as dimensões do exemplar são mais semelhantes à G. anglicum. O mesmo equívoco ocorreu em Tremarin et al. (2009a, p. 117, Fig.10), em que foi representado um indivíduo com razão comprimento/largura mais próxima de G. anglicum entre os indivíduos determinados como G. capitatum.

Hustedt (1930) apresenta três ilustrações de Navicula lagerheimii Cleve (Schmidt 1930, pl. 370, figs. 19-21) e propõe a nova variedade intermedia (Schmidt 1930, pl. 370, fig. 22), notavelmente com contorno mais linear e com área central menos expandida do que os outros exemplares. Entretanto, Hustedt (1961-1966) utiliza as mesmas ilustrações para designar a nova forma intermedia de Navicula mutica, utilizando como sinônimo Navicula lagerheimii sensu Hustedt (1921) e não sensu Cleve (1894). Embora Hustedt tenha se equivocado na identificação de $N$. lagerheimii em 1930 optou-se por utilizar a combinação proposta pelo mesmo autor em 1961-1966, pois os exemplares observados assemelham-se as formas descritas como $N$. mutica f. intermedia, e são notavelmente diferentes de $N$. lagerheimii, que apresenta estigma marginal em fenda e contorno valvar diferente do observado. Sugere-se que o material utilizado por Hustedt seja reexaminado, a fim de definir se os indivíduos com as características apresentadas nas quatro ilustrações realmente pertencem a uma única entidade taxonômica, ou se a designação da forma intermedia refere-se apenas aos indivíduos com contorno valvar mais linear. Embora o táxon claramente pertença ao gênero Luticola a nova combinação 
ainda não foi realizada, justificando o enquadramento no gênero Navicula.

A análise do complexo formado por Navicula notha, $N$. leptostriata Jørgensen e $N$. heimansioides Lange-Bertalot revelou que $N$. heimansioides e $N$. notha são variações morfológicas de um mesmo táxon, pois o único caráter utilizado para separar as espécies foi as maiores dimensões de $N$. heimansioides. Já $N$. notha e $N$. leptostriata podem ser distinguidas, pois a segunda espécie é menos silicificada, apresenta terminações proximais da rafe menos espaçadas, estrias mais delicadas (devido à presença de aréolas menores) e área central mais expandida (Morales 2001).

\section{Agradecimentos}

Ao Centro de Microscopia Eletrônica da Universidade Federal do Paraná, por permitir a utilização do Microscópio Eletrônico de Varredura; aos professores Maria Regina Torres Boeger e Olavo Araújo Guimarães, do Departamento de Botânica da Universidade Federal do Paraná, pela identificação da macrófita; à Coordenação de Aperfeiçoamento de Pessoal de Nível Superior pelas bolsas de pós-graduação; e ao Conselho Nacional de Desenvolvimento Científico e Tecnológico, pelo apoio financeiro (MCT/ $\mathrm{CNPQ} / \mathrm{CT}$-Hidro) e pela bolsa de produtividade científica à $\mathrm{Dr}^{\mathrm{a}}$. Thelma Alvim Veiga Ludwig.

\section{Referências Bibliográficas}

Barber, H.G. \& Haworth, E.Y. 1981. A guide to the morphology of the diatom frustule. The Freshwater Biological Association 44: 1-112.

Carter, J.R. \& Flower, R.J. 1988. A new species of Eunotia, E. pirla sp. nov. from Woolmer Pond and acid pool in the southeast of England. Diatom Research 1: 1-8

Cetto, J.M.; Leandrini, J.A.; Felisberto, S.A. \& Rodrigues, L. 2004. Comunidade de algas perifíticas no reservatório de Irai, Estado do Paraná, Brasil. Acta Scientiarum-Biological Sciences 26(1): 1-7.

Cleve, P.T. 1894. Synopsis of the naviculoid diatom. Kongliga Svenska Vetenskaps-Akademiens Handlingar 26(2): 1-194.

Falasco, E.; Blanco, S.; Bona, F.; Gomà, J.; Hlúbiková, D.; Novais, M.H.; Hoffmann, L. \& Ector, L. 2009 Taxonomy, morphology and distribution of the Sellaphora stroemii complex (Bacillariophyceae). Fottea 9(2): 243-256.

Felisberto, S.A. \& Rodrigues, L.C. 2005. Comunidade de algas perifíticas em reservatórios de diferentes latitudes. Pp. 97-114. In: Rodrigues, L.; Thomaz, S.M.; Agostinho, A.A. \& Gomes, L.C. (Orgs.). Biocenoses em reservatórios - padrões espaciais e temporais. São Carlos, Rima.

Fernandes, V.O. 2005 Perifíton: conceitos e aplicações da limnologia à engenharia, Pp. 351-370. In: Roland, F.; Cesar, D. \& Marinho, M. (Ed.) Lições de Limnologia. São Carlos, Rima.

Fernandes, V.O. \& Esteves, F.A. 2003. The use of indices for evaluating the periphytic community in two kinds of substrate in Imboassica lagoon, Rio de Janeiro, Brazil. Brazilian Journal of Biology 63(2): 223-232.

Frenguelli, J. 1933. Diatomeas de la región de los esteros del Yberá. Anales del Museo Nacional de Historia Natural 37: 365-476.

Fürstenberger, C.B. \& Valente-Moreira, I.M. 2000a. Diatomáceas (Bacillariophyta) perifíticas da lagoa Tarumã, Ponta Grossa, Paraná, Brasil. 1. Bacillariophycidae (exceto Eunotiaceae). Insula 29: 25-65.

Fürstenberger, C.B. \& Valente-Moreira, I.M. 2000b. Diatomáceas (Bacillariophyta) perifíticas da lagoa Tarumã, Ponta Grossa, Paraná, Brasil. 2. Eunotiaceae. Insula 29: 117-134.

Hendey, N.I. 1964. An introductory account of the smaller algae of British coastal waters - V. Bacillariophyceae (Diatoms), Fishery Investigations Series. London, H.M.S.O. 4: 1-317.

Hustedt F. 1930. Bacillariophyta (Diatomeas). In: Pascher A. (Ed.) Die Süsswasser-Flora Mitteleuropas. G. Fischer, Jena. 10: 1-466.

Hustedt, F. 1961-1966. Die Kieselalgen. In: Rabenhorst, L. KryptogamenFlora. Leipzig, Akademische Verlagsgesellschaft, 7(3): 1-816.
Krammer, K. 1997. Die cymbelloiden Diatomeen: eine monographie der weltweit bekannten taxa. II Encyonema Part., Encyonopsis and Cymbellopsis. Bibliotheca Diatomologica 37: 1-469.

Krammer, K. 2000. The genus Pinnularia. Diatoms of Europe 1: 1-703.

Krammer, K. 2002. Diatoms of the European inland waters and comparable habitats - Cymbella, Diatoms of Europe 3: 1-584.

Krammer, K. \& Lange-Bertalot, H. 1986. Bacillariophyceae: Naviculaceae. In: Ettl, H.; Gerloff, I.; Heynig, H. \& Mollenhauer, D. (Eds.). Siisswasserflora Von Mitteleuropa. Stuttgart, G Fischer, 2(1): 1-876.

Krammer, K. \& Lange-Bertalot, H. 1988. Bacillariophyceae: Bacillariaceae, Epithemiaceae, Surirellaceae. In: Ettl, H.; Gerloff, I.; Heynig H. \& Mollenhauer D. (Eds.), Süsswasserflora von Mitteleuropa. Jena, G. Fischer. 2(2): 1-596.

Krammer, K. \& Lange-Bertalot, H. 1991. Bacillariophyceae: Centrales, Fragilariaceae, Eunotiaceae. In: Ettl. H.; Gerlloff, I.; Heynig, H. \& Mollenhauer, D. (Eds.). Süsswasser-Flora von Mitteleuropa. Jena, G. Fischer. 2(3): 1-576.

Lange-Bertalot, H. \& Simonsen, R. 1978. A Taxonomic revision of the Nitzschiae lanceolatae Grunow 2. European and Related ExtraEuropean Fresh Water and Brackish water taxa. Bacillaria 11: 11-111.

Lange-Bertalot, H. \& Metzeltin, D. 1996. Oligotrophie indikatoren. 800 taxa repräsentativ für drei diverse see-typen, kalkreich - oligodystroph schwach gepuffertes weichwasser. Iconographia Diatomologica 2: 1-390.

Lowe, R.L. 1996. Periphyton patterns in lakes. Pp. 57-76. In: Stevenson, R.J., Bothwell, M.L. \& Lowe, R.L. (Eds.) Algal ecology: Freshwater Benthic Ecossystems. San Diego, Academic Press.

Lozovei, A.L. \& Shirata, M.T. 1990. Diatomáceas (Chrysophyta, Bacillariophyceae) no Rio Passaúna, Curitiba, Paraná, Brasil Levantamento qualitativo da diatomoflórula em segmento manancial. Estudos de Biologia 27: 5-56.

Ludwig, T.A.V. \& Valente-Moreira, I.M. 1989. Contribuição ao conhecimento da diatomoflórula do Parque Regional do Iguaçu, Paraná, Brasil: I. Eunotiaceae (Bacillariophyceae). Arquivos de Biologia e Tecnologia 3(32): 543-650.

Ludwig, T.A.L. \& Valente-Moreira, I.M. 1990. Contribuição ao conhecimento da diatomoflórula do parque regional do Iguaçu, Curitiba, Paraná, Brasil: II. Cêntricas (Bacillariophyceae). Arquivos de Biologia e Tecnologia 3(4): 843-852.

Ludwig, T.A.V.; Bigunas, P.I.T.; Neiva, T.F.; Coquemala, V. \& Piccinini, C. 2005. Diatomáceas (Ochorophyta) dos Lagos do Jardim Botânico, Curitiba, Paraná. Pp. 301-323. In: Anais da X Reunião Brasileira de Ficologia. Rio de Janeiro, Sociedade Brasileira de Ficologia.

Ludwig, T.A.V.; Flores, T.L.; Moreira-Filho, H. \& Veiga, L.A.S. 2004. Inventário florístico das diatomáceas (Ochrophyta) de lagoas do Sistema Hidrológico do Taim, Rio Grande do Sul, Brasil: Coscinodiscophyceae. Iheringia - Série Botânica 59(1): 97-106.

Maack, R. 1981. Geografia física do Estado do Paraná. 2. ed. Curitiba, Secretaria da Cultura e do esporte do Governo do Estado do Paraná.

Maidana, N.I. \& Seeligmann, C. 2006. Diatomeas (Bacillariophyceae) de ambientes acuáticos de altura de La Provincia de Catamarca, Argentina II. Boletín de la Sociedad Argentina de botánica 41: 1-13.

Mann, D.G.; Thomas, S.J. \& Evans, K.M. 2008. Revision of the diatom genus Sellaphora: a first account of the larger species in the British Isles. Fottea 8(1): 15-78.

Metzeltin, D. \& Lange-Bertalot, H. 1998. Tropical Diatoms of South America. Iconographia Diatomologica 5: 1-220.

Metzeltin, D. \& Lange-Bertalot, H. 2002. Diatoms from the "Island Continent" Madagascar. Iconographia Diatomologica 11: 1-320.

Metzeltin, D., Lange-Bertalot, H. \& García-Rodrígues, F. 2005. Diatoms of Uruguay. Iconographia Diatomologica 15: 1-736.

Morales, E.A. 2001. Fourth NAWQA Diatom Taxonomy Harmonization Workshop. Patrick Center for Environmental Research. The Academy of Natural Sciences of Philadelphia.

Morales, E.A. 2005. Observations of the morphology of some known and new fragilarioid diatoms (Bacillariophyceae) from Rivers in the USA. Phycological Research 53: 113-133.

Moreira-Filho, H.; Valente-Moreira, I.M. \& Cecy, I.I.T. 1973. Diatomáceas na barragem de captação d'água (SANEPAR) do rio Iguaçu, em Curitiba, Estado do Paraná. Acta Biológica Paranaense 2(1-4): 133-145. 
Moreira-Filho, H. \& Valente Moreira, I.M. 1981. Avaliação taxonômica e ecológica das diatomáceas (Bacillariophyceae) epífitas em algas pluricelulares obtidas nos litorais dos Estados do Paraná, Santa Catarina e São Paulo. Boletim do Museu Botânica Municipal 47: 1-17.

Moro, R.S. \& Fürstenberger, C.B. 1993. Diatomáceas (Bacillariophyaceae) da lagoa Dourada (Parque Estadual de Vila Velha), Paraná, Brasil. Acta Biológica Paranaense 22(1-4): 15-30.

Moser, G.; Steindorf, A. \& Lange-Bertalot, H. 1995. Neuekaledonien. Diatomeenflora einer Tropeninsel. Reviosion der Collection Maillard und Untersuchung neuen Materials. Bibliotheca Diatomologica 32: 1-340.

Moutinho, S.O.; Garcia, M.J. \& Oliveira, P.E. 2007. Flora diatomáceas do Reservatório Cabuçu, Município de Guarulhos, SP: Análise qualitativa. Revista UnG - Geociências 6(1): 32-62.

Pompêo, M.L.M. \& Moschini-Carlos, V. 2003. Macrófitas aquáticas e perifíton - Aspectos ecológicos e metodológicos. São Carlos, Rima.

Reichardt, E. 1997. Taxonomische Revision des Artenkomplexes um Gomphonema pumilum (Bacillariophyceae), Nova Hedwigia (65). 99-129.

Reichardt, E. 2001. Revision of the species around Gomphonema truncatum and G. capitatum. Pp. 187-224. In: Jahn, R.; Kociolek, J.P.; Witkowsji, A.; Compère P. (Eds.). Lange-Bertalot Festschrift: Studies on Diatoms. Ruggel, A.R.G. Gantner Verlag.

Rodrigues, L. 1991. Naviculaceae (Bacillariophyceae) nas lagoas do horto florestal Dr. Luiz Teixeira Mendes, município de Maringá, Paraná, Brasil. Revista UNIMAR 13(2): 273-298.

Rodrigues, L. \& Bicudo, D.C. 2001. Similarity among periphyton algal communities in a lentic-lotic gradient of the upper Paraná river floodplain, Brazil. Revista Brasileira de Botânica 24(3): 235-248.

Round, F.E.; Crawford, R.M. \& Mann, D.G. 1990. The diatoms, biology and morphology of the genera. New York, Cambridge University Press.

Rumrich, U.; Lange-Bertalot, H. \& Rumrich, M. 2000. Diatomeen der Anden von Vezezuela bis Patagonien / Tierra del Fuego. Iconographia Diatomologica 9: 1-650.

Salomoni, S.E. \& Torgan, L.C. 2008. Epilithic diatoms as organic contamination degree indicators in Guaíba Lake, Southern Brazil. Acta Limnologica Brasiliensia 20(4): 313-324.

Sauniti, R.M.; Fernandes, L.A. \& Bittencourt, A.V.L. 2004. Estudo do assoreamento do reservatório da barragem do rio Passaúna-CuritibaPR, Boletim Paranaense de Geociências 54: 65-82.

Schmidt, A. 1930. Atlas der Diatomaceen - Kunde. Reisland, Leipzing. Shirata, M.T. \& Valente-Moreira, I.M. 1987. Ocorrência das diatomáceas Attheya zachariasi e Surirella stalagma no lago Parque São Lourenço,
Curitiba, PR, Brasil. Acta Biológica Paranaense 16(1-4): 87-92.

Shirata, M.T. \& Valente-Moreira, I.M. 1989. Coscinodiscaceae (Bacillariophyceae) no lago Parque São Lourenço, Curitiba, Estado do Paraná, Brasil. Estudos de Biologia 21: 3-23.

Seeligmann, C.; Maidana, N.I. \& Morales, M. 2008. Diatomeas (Bacillariophyceae) de humedales de altura de la Provincia de Jujuy-Argentina. Boletín de la Sociedad Argentina de Botánica 43(1-2):1-17.

Simonsen, R. 1974. The diatom plankton of the Indian Ocean expedition of R/V "Meteor", 1964-1965. Meteor. Forschungsergebnisse Reihe D-Biologie 19: 1-66.

Simonsen, R. 1987. Atlas and catalogue of the diatom types of Friedrich Hustedt. v. 2. Berlin, J. Cramer.

Smaha, N.; Gobbi, M.F. 2003. Implementação de um modelo para similar a eutrofização do Reservatório do Passaúna - Curitiba - PR. Revista Brasileira de Recursos Hídricos 8(3): 59-69.

Souza, M.G.M. \& Moreira-Filho, H. 1999a. Diatoms (Bacillariophyceae) of two aquatic macrophytes banks from Lagoa Bonita, Distrito Federal, Brazil, I: Thalassiosiraceae and Eunotiaceae. Bulletin du Jardin Botanique National de Belgique 67: 259-278.

Souza, M.G.M. \& Moreira-Filho, H. 1999b. Diatoms (Bacillariophyceae) of two aquatic macrophyte banks from Lagoa Bonita, Distrito Federal, II: Navicula and Pinnularia. Bulletin du Jardin Botanique National de Belgique 67: 279-288.

Tavares, B. \& Valente-Moreira, I. M. 2000. Diatomoflórula do lago de Cascavel, município de Cascavel, estado do Paraná, Brasil. Hoehnea 27(1): 1-24.

Torgan, L.C.; Salomoni, S.E. \& Bicca, A.B. 2009. Diatomáceas sobre Limnoperma fortunei (Dunker), molusco introduzido no Lago Guaíba, Sul do Brasil. Revista Brasileira de Botânica 32(1): 23-31.

Tremarin, P.I.; Bertolli, L.M.; Faria, D.M. \& Ludwig, T.A.V. 2009a. Gomphonema Ehrenberg e Gomphosphenia Lange-Bertalot (Bacillariophyceae) do Rio Maurício, Paraná, Brasil. Biota Neotropica 9(4): http://www.biotaneotropica.org.br/v9n4/pt/abstract?inventory+ bn00309042009.

Tremarin, P.I.; Freire, E.G.; Bertolli, L.M. \& Ludwig, T.A.V. 2009b. Catálogo das diatomáceas (Ochrophyta-Diatomeae) continentais do estado do Paraná. Iheringia - Série Botânica 64(2): 79-107.

Vercellino, I.S. \& Bicudo, D.C. 2006. Sucessão da comunidade de algas perifíticas em reservatório oligotrófico tropical (São Paulo, Brasil): comparação entre período seco e chuvoso. Revista Brasileira de Botânica 29(3): 363-377.

Wetzel, R.G. 1993. Limnologia. Lisboa, Fundação Calouste Gulbenkian.

Versão eletrônica do artigo em www.scielo.br/abb e http://www.botanica.org.br/acta/ojs 